Put, J. E., G. W. Mitchell, N. A. Mahony, J. Costa, T. L. Imlay, S. Bossuyt, C. Boynton, G. Burness, D. R. Evans, K. A. Hobson, J. W. Kusack, O. Lansdorp, A. K. Lenske, B. McClenaghan, E. Nol, A. Salvadori, A. C. Smith, T. D. Williams, B. Whittam, and M. D. Cadman 2021. Regional variability in trajectories of Barn Swallow populations across Canada are not predicted by breeding performance. Avian Conservation and Ecology 16 (2):10. https://doi.org/10.5751/ACE-01933-160210

Copyright (C) 2021 by the author(s). Published here under license by the Resilience Alliance.

Research Paper

\title{
Regional variability in trajectories of Barn Swallow populations across Canada are not predicted by breeding performance
}

Julia E. Put ${ }^{1}$, Greg W. Mitchell ${ }^{2,3}$, Nancy A. Mahony ${ }^{4}$, Jeffrey Costa ${ }^{5}$, Tara L. Imlay ${ }^{6,7}$, Scott Bossuyt $^{8}$, Chloe K. Boynton ${ }^{6,9}$, Gary Burness $^{8}$, Dean R. Evans ${ }^{10}$, Keith A. Hobson ${ }^{10}$, Jackson W. Kusack ${ }^{10}$, Olga Lansdorp ${ }^{9}$, Ariel K. Lenske ${ }^{11}$, Beverly Mc Clenaghan ${ }^{11,12}$, Erica Nol ${ }^{8}$, Antonio Salvadori, Adam C. Smith ${ }^{1}$, Tony D. Williams ${ }^{9}$, Rebecca Whittam ${ }^{13}$ and Michael D. Cadman $^{5}$

${ }^{1}$ Environment and Climate Change Canada, Canadian Wildlife Service, Ottawa, Ontario, Canada, ${ }^{2}$ Environment and Climate Change Canada, Wildlife Research Division, Ottawa, Ontario, Canada, ${ }^{3}$ Department of Biology, Carleton University, Ottawa, Ontario, Canada, ${ }^{4}$ Environment and Climate Change Canada, Wildlife Research Division, Edmonton, Alberta, Canada,

${ }^{5}$ Environment and Climate Change Canada, Canadian Wildlife Service, Burlington, Ontario, Canada, ${ }^{6}$ Environment and Climate Change Canada, Canadian Wildlife Service, Delta, British Columbia, Canada, ${ }^{7}$ Department of Biology, Dalhousie University, Halifax, NS, Canada, ${ }^{8}$ Department of Biology, Trent University, Peterborough (Nogojiwanong), Ontario, Canada, ${ }^{9}$ Center for Wildlife Ecology, Department of Biological Sciences, Simon Fraser University, Burnaby, British Columbia, Canada, ${ }^{10}$ Department of Biology, University of Western Ontario, London, Ontario, Canada, ${ }^{11}$ Environmental and Life Sciences Graduate Program, Trent University, Peterborough, Ontario, Canada, ${ }^{12}$ Centre for Environmental Genomics Applications, St. John's, Newfoundland and Labrador, Canada, ${ }^{13}$ Environment and Climate Change Canada, Canadian Wildlife Service, Sackville, New Brunswick, Canada

\begin{abstract}
Conservation of migratory species depends on an understanding of the drivers causing population declines across the annual cycle. Since it is difficult to track the entire annual cycle for long-distance migrants, measurements from part of the cycle may provide insights into overall drivers. Barn Swallows (Hirundo rustica) in Canada have undergone steep and long-term population declines. Using Breeding Bird Survey data and breeding performance data collected at field sites in three regions across Canada, we examined long- and short-term Barn Swallow population trends in Canada, differences in breeding performance across regions, if average breeding performance measures or colony size predicted regional population growth rates and if local breeding performance is driven by density dependence and/or recruitment. We found that long-term negative population trends were generally stronger in the east and west, and weaker in central Canada. Short-term population trends were generally weakly negative or neutral. Average breeding performance and colony size were poor predictors of regional growth rates observed in the subsequent year. We found little support for density dependence affecting local breeding performance; however, local breeding success, presumably through subsequent recruitment of young, was positively correlated to changes in local colony size in the following year. Since we found juveniles recruited into colonies located in the same region, but no link between average breeding performance and estimated regional population trajectories, our results suggest that extrapolating from local-scale studies to broader populations is challenging, and other demographic rates (i.e., survival) may need to be considered. Overall, our study suggests that contemporary Barn Swallow populations are below carrying capacity in Canada, further suggesting that food limitation is not currently regulating populations. Further study is needed to understand what factors are limiting and regulating Barn Swallow populations in Canada, across the annual cycle.
\end{abstract}

\section{La variabilité régionale des trajectoires des populations d'hirondelles rustiques dans l'ensemble du Canada n'est pas liée à la performance reproductrice}

RÉSUMÉ. La conservation des espèces migratrices requiert une bonne compréhension des éléments qui provoquent le déclin des populations sur l'ensemble du cycle annuel. Comme il est difficile de suivre l'intégralité du cycle annuel dans le cas des espèces migratrices parcourant de longues distances, les mesures réalisées sur certaines parties du cycle pourraient fournir des informations au sujet des raisons globales de cette évolution. Au Canada, les populations d'hirondelles rustiques ont connu un déclin vertigineux et durable. En utilisant les données de l'enquête sur la reproduction des oiseaux et les données de performance reproductrice collectées sur le terrain dans trois régions du Canada, nous avons examiné les tendances à long et à court terme des populations d'hirondelles rustiques au Canada, les différences en termes de reproduction entre les régions, la comparaison entre la performance reproductrice moyenne ou la taille des colonies et le taux de croissance prévu des populations régionales et les effets éventuels de la dépendance de la densité et/ou du recrutement sur la performance reproductrice locale. Nous avons constaté que les tendances négatives à long terme étaient généralement plus fortes dans l'est et dans l'ouest, et plus faibles au centre du Canada. Les tendances à court terme des populations étaient généralement légèrement négatives ou neutres. La performance reproductrice moyenne et la taille des colonies étaient de mauvais indicateurs des taux de croissance régionaux observés au cours de l'année suivante. Peu de signes indiquent que la dépendance de la densité affecte la performance reproductrice locale ; toutefois, le succès de la reproduction locale, éventuellement par le recrutement 
ultérieur de jeunes, semble aboutir à des évolutions positives de la taille des colonies locales au cours de l'année suivante. Dans la mesure où nous avons trouvé des jeunes qui avaient été recrutés dans des colonies installées dans la même région, mais aucun lien entre la performance reproductrice moyenne locale et l'évolution estimée de la population régionale, nos résultats suggèrent que l'extrapolation à partir d'études à échelle locale sur les populations plus larges est difficile, et qu'il faut tenir compte d'autres facteurs démographiques (par ex. le taux de survie). Globalement, notre étude indique que les populations contemporaines d'hirondelles rustiques se situent sous la capacité biotique au Canada, ce qui suggère également que les limites de ressources alimentaires ne régulent pas actuellement les populations. D'autres études sont nécessaires pour comprendre les facteurs qui limitent et régulent les populations d'hirondelles rustiques au Canada, tout au long du cycle annuel.

Key Words: avian aerial insectivore; Hirundo rustica; migratory bird; North American Breeding Bird Survey; population trend; species at risk

\section{INTRODUCTION}

For conservation practitioners, measurements of breeding performance and their variation is critical for understanding animal population growth rates and drivers of decline (Noon and Sauer 1992, Caswell 2000, Wisdom et al. 2000, Zipkin and Saunders 2018, Weiser et al. 2020). Most studies that measure breeding performance occur at the scale of local or subpopulations, and are often unable to account for variation in breeding performance across the broader population (Noon and Sauer 1992, but see McNew et al. 2012, Shutler et al. 2012). Moreover, population dynamics are often estimated from local breeding performance metrics (e.g., McNew et al. 2012) instead of count surveys, likely because of the challenges of monitoring broadly distributed or diffuse populations through time. This is problematic for two reasons. First, population trajectories estimated from local breeding performance, may not correspond to trajectories estimated through count surveys if unmeasured vital rates (e.g., adult survival rates) are more important than measured rates (e.g., breeding success). Second, local trends may not match those of the broader population if limiting factors vary across landscapes, regions, or sub-populations. Therefore, the conservation of broadly distributed species requires an assessment of variability in breeding performance across a species's range, as well as region-specific population trends to understand factors driving population change.

Barn Swallows (Hirundo rustica) breeding in Canada have undergone steep population declines of up to $70 \%$ since the 1970 s (COSEWIC 2011), resulting in their federal listing as "threatened" under the Species-at-Risk Act (SARA 2019), but there is little empirical evidence for the drivers of population decline. Declines may be caused by factors acting during one or more parts of the annual cycle (breeding, migration, wintering) as Barn Swallows breeding in Canada migrate from Central and South America (Hobson et al. 2015). Factors hypothesized to threaten Barn Swallows include habitat loss (Spiller and Dettmers 2019), agricultural intensification (Evans et al. 2007, Billeter et al. 2008, Stanton et al. 2018; but see Boynton et al. 2020, Kusack et al. 2020), including pesticide use (Hallmann et al. 2014), and changes in weather and climate (García-Pérez et al. 2014b) on the breeding grounds as well as on the wintering grounds (Hansen et al. 2013, Laurance et al. 2014). Breeding ground factors can have an effect on density dependence and juvenile recruitment prior to fall migration (Sherry and Holmes 1995). For instance, larger colonies could have a low number of young that fledge per nest or lower recruitment due to limited prey. Alternatively, colonies could have greater average reproductive success due to favorable weather conditions, which, in turn, results in higher nest occupancy the following year. For Barn Swallows, long-term population declines have generally occurred across Canada (Michel et al. 2016) but are strongest in the east (Nebel et al. 2010). If contemporary population sizes are at carrying capacity, we expect density dependence to be operating, most likely through food limitation on the breeding grounds associated with agricultural intensification. Alternatively, the lack of evidence of density dependence suggests contemporary populations are below carrying capacity. Therefore, the first step to understanding if factors on the breeding grounds are limiting Barn Swallow populations is to examine the effect of density dependence on breeding performance.

If variation in population trends is caused at least partly by factors on the breeding grounds, then variation in breeding productivity within regions may be positively correlated with population growth rates the following year (Siriwardena et al. 2000). For example, in Denmark, Møller (1989) observed that Barn Swallow breeding success in year $\mathrm{X}$ positively predicted abundance in the subsequent year (i.e., X+1). Conversely, Siriwardena et al. (2000) found no evidence for a correlation between breeding productivity and population trends for 12 granivorous bird species in Britain. Evidence like the latter, where breeding performance does not relate to population growth rates, suggests greater contributions from survival (Sæther and Bakke 2000, Taylor et al. 2018), likely outside the breeding period, and/or dispersal (Weegman et al. 2016). For example, non-breeding survival was found to be the primary driver of Canada Warbler (Cardellina canadensis) declines observed on the breeding grounds (Wilson et al. 2018).

Our study took advantage of a rare opportunity where multi-year data on Barn Swallow breeding performance were collected in three study regions in western, central, and eastern Canada. Using these data, our overarching objective was to compare regional breeding performance and population trends, and to examine population dynamic factors. We quantified (1) long-term (i.e., 1970-2018) and short-term (i.e., 2009-2018) regional population trends. To determine if breeding performance was similar among the three study regions, we quantified (2) variation in breeding performance (nest success and number of young produced per nest) across study regions. To determine if study region breeding performance was related to changes in annual population indices, we tested whether (3) average breeding performance and colony sizes in year $\mathrm{X}$ predict annual indices from intersections of province/territory and Bird Conservation Regions (BCR) in year $\mathrm{X}+1$. A positive relationship between these variables suggests that relatively local measurements of breeding performance within regions can be used to predict changes in regional population indices. Next, we focused on the potential effects of density- 
dependence and recruitment on local colony sizes or breeding performance. To determine if density dependence affects population sizes, we tested whether (4) local colony sizes predicted local breeding performance in the same year. To determine if recruitment (i.e., addition of breeding pairs) factors affect population size, we tested if (5) local breeding performance in year $\mathrm{X}$ predicted changes in local colony size from year $\mathrm{X}$ to year $\mathrm{X}+1$.

Importantly, our objectives provide insight into carrying capacity. Negative correlations between local breeding performance and colony size (objective 4) would suggest that density dependence is regulating current breeding populations. This in turn would suggest that populations are at carrying capacity, and those populations may be experiencing food limitation on the breeding grounds. A lack of correlation between local population size and breeding performance would suggest populations are below carrying capacity and that food may not be limiting. Moreover, if we found that average breeding performance and colony size in year $\mathrm{X}$ predicts regional population indices in year $\mathrm{X}+1$ (objective 3 ) or that local reproductive performance in year $X$ predicts local population size in year $\mathrm{X}+1$ (objective 5), it would suggest that populations are below carrying capacity and that food is not limiting on the breeding grounds.

\section{METHODS}

\section{Overview}

We examined temporal and spatial variation in Barn Swallow population trends and breeding performance across Canada with a multi-step analysis. First, to determine short-term (2009-2018) and long-term (1970-2018) regional population trajectories and relative population sizes (Objective 1), we derived North American Breeding Bird Survey (BBS) data (Link et al. 2017) annual indices from hierarchical Bayesian models that used Barn Swallow data from regions stratified by intersections of province/ territory and BCR (NABCI Canada 2019). Second, to observe if there was spatial and temporal variation in breeding performance across Canada (Objective 2), we performed generalized linear models on breeding performance data collected in three BBS strata located in eastern, central, and western Canada from 2013 to 2016. Third, to examine whether local breeding performance measures could be used to predict regional population growth rates (Objective 3), we used general linear mixed-models to model the relationship between local breeding performance and colony sizes in year $\mathrm{X}$ with regional annual indices derived from BBS data in year $\mathrm{X}+1$. Last, we modelled relationships at the colonies to determine the effect of density dependence on reproductive performance (Objective 4), and the effect of breeding performance on recruitment (Objective 5).

\section{Barn Swallow BBS population growth rates and trends}

To summarize patterns in Barn Swallow population growth rates, trends, and the size of remaining populations in Canada, we used BBS data. By growth rates, we refer to year-to-year changes in annual indices while trend refers to percent change in annual indices over a multi-year time period. BBS data are collected from standardized roadside point-count surveys performed along permanent routes by volunteers (Sauer et al. 2017). In Canada, the surveys are generally conducted in June, at the height of the breeding period of most bird species (Sauer et al. 2017). BBS data are screened for unacceptable conditions, such as rain and high winds (GOC 2019).

We estimated annual indices of abundance and trends from the BBS using hierarchal Bayesian models and Markov chain Monte Carlo (MCMC) methods with the bbsBayes R package (Smith and Edwards 2020). The annual index represents the estimated average abundance of a species on BBS routes run in a given year by an average observer in that stratum. The hierarchical Bayesian models allow for different modelling approaches for extracting annual indices. We used three approaches for different parts of the analysis, depending on our objectives: (1) generalized additive model (GAM), (2) slope, and (3) first-difference models. As per our first objective, population trends were derived and visualized for 24 strata in Canada to show relative short and long-term trends. To estimate long-term trends (47-year trend from 1970-2018; Fig. 1A), we used the GAM approach because it estimates non-linear smooth trajectories that allow for stable trend estimates without assuming a constant rate of change over the 48-year time series (Smith and Edwards 2020). To estimate short-term trends (9-year trend from 2009-2018; Fig. 1B), we used trends based on the slope model because over a short time period the assumption of a constant rate of change is reasonable and it allows for a single estimate of change for the period of interest. In total, we examined trends for 24 out of 27 possible strata across Canada, defined by intersections of province/territory and BCR. The three unexamined strata were either out of the geographic range of Barn Swallows or had insufficient data. We used the firstdifference approach to track annual rates of change between successive years in strata where breeding performance measures were collected (see population indices and breeding performance section in Methods). The first-difference approach uses a firstdifference smoother for the intercept, shifting effects of year towards adjacent year values rather than the trend line (Link et al. 2017) and estimates each BBS stratum annual index independent of other BBS strata.

\section{Canada-wide breeding performance data}

We compiled Barn Swallow nesting data from barns or other buildings (hereafter colonies) located in western, central and eastern Canada (Fig. 2, Table 1). Data from western Canada were collected from 2013 to 2016 in southwestern British Columbia in BCR 5, hereafter British Columbia. Data from central Canada in BCR 13 came from two studies; one in southwestern Ontario and one in southcentral Ontario in 2006 to 2018 and 2014 to 2016 , respectively. Data from eastern Canada were collected from 2011 to 2017 in BCR 14 primarily in New Brunswick (11 out of 13 colonies), hereafter New Brunswick. Data collected at the other two colonies in eastern Canada were located in Nova Scotia. We identified two breeding performance measures that could be compared across the field sites: nest success [1 if at least one young survived, 0 if no young or eggs survived] and number of young produced per nest [brood size $\mathrm{x}$ nest success]. We removed nests from our analysis that had clutch sizes $>7(n=8)$, because we assumed egg-dumping had occurred (Møller 1987). We also summarized average clutch size [maximum number of eggs recorded per nest] and brood size [maximum number of nestlings recorded per nest] for each study region. Nesting data from 
Table 1. Locational information about field sites in Canada where Barn Swallow breeding performance was measured. The table includes the Bird Conservation Region (BCR) and corresponding number (in brackets) that the field sites were located in and the geographic coordinates of the center point of each field site (in degrees, minutes, seconds).

\begin{tabular}{lll}
\hline \hline Field site & BCR & Center point of field site (DMS) \\
\hline British Columbia & British Columbia Northern Pacific Rainforest (5) & $49^{\circ} 10^{\prime} 44.2^{\prime \prime} \mathrm{N}, 123^{\circ} 5^{\prime} 49.0^{\prime \prime} \mathrm{W}$ \\
southwestern Ontario & Ontario Lower Great Lakes/St. Lawrence Plain (13) & $43^{\circ} 39^{\prime} 3.2^{\prime \prime} \mathrm{N}, 80^{\circ} 12^{\prime} 59.3^{\prime \prime} \mathrm{W}$ \\
southcentral Ontario & Ontario Lower Great Lakes/St. Lawrence Plain (13) & $44^{\circ} 19^{\prime} 17.0^{\prime \prime} \mathrm{N}, 78^{\circ} 24^{\prime} 20.9^{\prime \prime} \mathrm{W}$ \\
New Brunswick & $11 / 13$ colonies in New Brunswick Atlantic Northern Forests (14) and 2/13 & $45^{\circ} 52^{\prime} 54.8^{\prime \prime} \mathrm{N}, 64^{\circ} 15^{\prime} 9.6^{\prime \prime} \mathrm{W}$ \\
& colonies in Nova Scotia Atlantic Northern Forests (14) & \\
\hline
\end{tabular}

Fig. 1. Annual percent change in the Barn Swallow (Hirundo rustica) population in Canada from (A) 1970 to 2018 and (B) 2009 to 2018, and annual population index in (C) 1970 and (D) 2018 stratified by intersections of province/territory region and Bird Conservation Regions. The annual index represents the estimated average abundance of Barn Swallows on Breeding Bird Survey (BBS) routes run in a given year by an average observer in that stratum. The population trends were derived from the annual indices. The annual indices were calculated using hierarchical Bayesian models using the GAM approach in $\mathrm{A}, \mathrm{C}$, and D and the slope approach in B. In regions shaded gray there are no BBS routes, Barn Swallows are not present, or Barn Swallows have insufficient data.

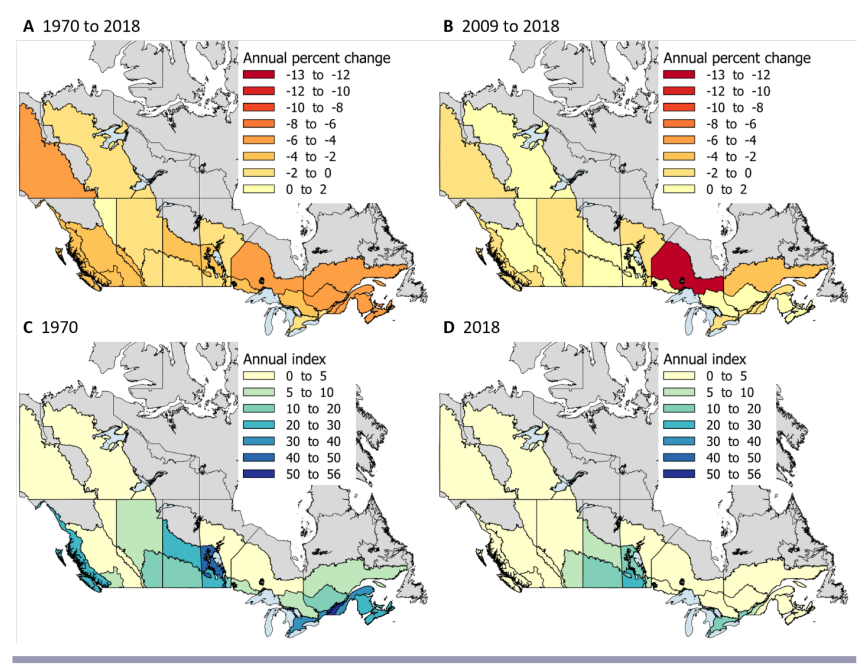

colonies that experienced whole colony failure due to predation events, e.g., by American red squirrels (Tamiasciurus hudsonicus; $\mathrm{n}=2$ ) and Cooper's hawk (Accipiter cooperii; $\mathrm{n}=1$ ) in Guelph, Ontario, were removed from the analysis because we expected that they would not be reflective of regional processes.

Since breeding performance data in each individual study were collected for different purposes, the number of visits to the active nests and length of time that nests were monitored varied slightly between studies. Research projects in British Columbia and southcentral Ontario monitored nests until nestlings fledged (around Day 20). In southwestern Ontario, nests were monitored until nestlings were old enough to be banded (typically Day 6-10) from 2006 to 2015 and then from 2016 to 2018 were monitored until fledging (Day 20). In New Brunswick, nests were monitored
Fig. 2. Locations of colonies where Barn Swallow (Hirundo rustica) breeding performance was studied in three Breeding Bird Survey strata, British Columbia - Bird Conservation Region (BCR) 5, Ontario - BCR 13, and New Brunswick BCR14.

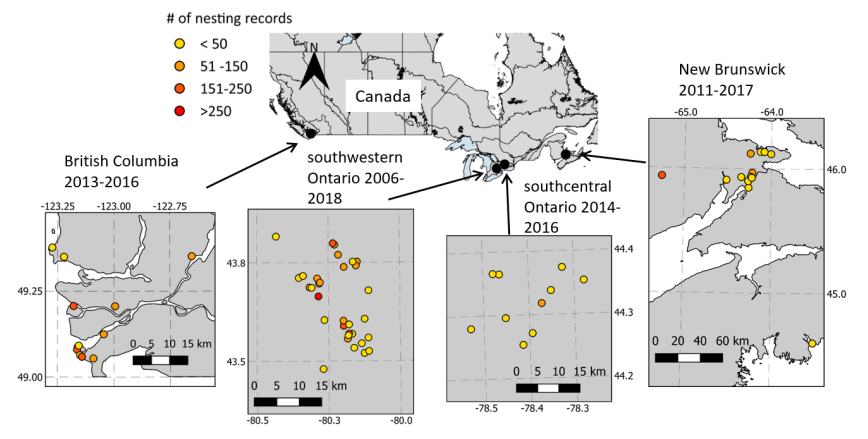

until nestlings fledged from 2011 to 2013 and then in 2014 to 2017 they were monitored until nestlings were 12 days old. To compare breeding performance across study regions, we considered a nest to be successful if nestlings reached Day 8 to 12 . If multiple visits were made to a nest during that period, we used nest success information from the later date (e.g., Day 12). Approximately $1 \%$ (5 nests out of 548) of nests failed in 2016 and 2017 in southwestern Ontario between Day 8 and Day 15. In British Columbia, $4.5 \%$ (25 nests out of 560) of nests failed after nestlings reached 10 days of age. This and other observations (Ambrosini et al. 2002) suggest that a nest reaching Day 8 was strongly indicative of it reaching at least Day 12. In all studies, nestlings were not counted after Days 12-15 to minimize risk of premature fledging.

\section{Spatial and temporal effects on breeding performance}

To test whether spatial (study region) and temporal factors (year and clutch initiation date) were good predictors of local breeding performance, we used data from 2013 to 2016 from British Columbia, southwestern Ontario, and New Brunswick. Relationships were modeled using generalized linear mixed models with a binomial distribution for nest success and a zeroinflated Poisson distribution for number of young produced given numerous zeros in the dataset. We included ten candidate models for each response variable (nest success and young produced) that 
included study region (British Columbia, southwestern Ontario, or New Brunswick), year (2013, 2014, 2015, or 2016) and clutch initiation date as predictor variables. We included candidate models with an interaction between study region and year. In all models there was a random effect for colony. The ten candidate models were: (1) Region * Year + Clutch initiation date, (2) Region + Year + Clutch initiation date, (3) Region* Year, (4) Region + Year, (5) Region + Clutch initiation date, (6) Region, (7) Year + Clutch initiation date, (8) Year, (9) Clutch initiation date, and (10) intercept-only. Year was treated as a categorical variable because it had a non-linear relationship with the response variables and a limited number of overlapping sampling years (i.e., four years) were available at all of the field sites. Clutch initiation date was included to account for differences in nest success and number of young produced during the breeding season because clutch initiation date is known to influence these breeding parameters (Brown and Brown 2019).

For the remaining analyses below, we expanded our use of the available nesting data. We made use of all years of data that were available in each study region: 2013 to 2016 in British Columbia, 2006 to 2018 in southwestern Ontario and 2011 to 2017 in New Brunswick. Additionally, we combined nesting data from 302 nests collected in southcentral Ontario from 2014 to 2016 with the data from southwestern Ontario because they were both found in the same BBS stratum (Ontario BCR 13). Nests found at the two colonies located outside the New Brunswick-BCR 14 BBS stratum in the eastern Canada region were not included. We also removed 2007 data from the Ontario BCR 13 region because breeding performance was monitored for a limited number of nests $(n=9)$.

\section{Population indices and breeding performance}

We examined whether there was a relationship between average breeding performance measures and the subsequent year's observed population growth rates in each of the three BBS strata (transect of province/territory and BCR) that encompassed the field sites using model selection. The relationship between average breeding performance measures and annual population growth rates were modeled using general linear mixed models. Our measure of population growth rates were annual indices. Annual indices were estimated with a hierarchical Bayesian model using the first-difference approach on BBS data collected in the strata that encompassed each field site for the 2006 to 2018 time period since our earliest breeding performance data was from 2006 . We used the first-difference approach because the estimates of each stratum's trajectory are treated independently of all other strata. To put the annual indices on a similar scale between BBS strata, we divided the annual indices by the average annual index across the evaluated time period in each stratum. This resulted in values with a mean of 1 that ranged from 0.88 to 1.09 . Previously we evaluated detrended annual indices, but the slightly negative short-term trend and larger population sizes in Ontario resulted in high variation in estimates while the neutral trends and smaller population sizes in British Columbia and New Brunswick resulted in little to no variation in estimates, and were not on comparable scales as a result. We linked average breeding performance in each year to the regional growth rate in the following year. For example, average breeding performance from Ontario in BCR 13 in 2013 was linked to the annual population index value from Ontario in BCR 13 in 2014. If Barn Swallow breeding performance had an effect on observed annual indices the following year, that would suggest juvenile recruitment had an effect on growth rate. In all models there was a random effect for year. Initially, year was included as a predictor variable to account for temporal correlation, but it had high relative variable importance in the model sets making it difficult to determine the importance of other variables. We examined eleven candidate models: (1) Mean colony size * Region, (2) Mean nest success * Region, (3) Mean young produced $*$ Region, (4) Mean colony size + Region, (5) Mean nest success + Region, (6) Mean young produced + Region, (7) Mean colony size, (8) Mean nest success, (9) Mean young produced, (10) Region and (11) intercept-only.

\section{Density dependence}

To test for density dependence, we used model selection to examine if local colony size predicted local breeding performance (nest success and young produced) in the same year. Colony size was defined as the number of monitored nests in a colony, including first and second broods. All nests in each colony were monitored. Generalized linear mixed-models were used to estimate the relationships with a beta distribution for models with proportion of successful nests per colony as the response variable. Some of the colonies had $100 \%$ nest success in some years (52 colony-year combinations out of 224) and there was a strong negative skew to the distribution, so 0.01 was subtracted from the average proportion of successful nests values to meet the requirements for a beta distribution. General linear mixed models were used to estimate the relationships for models with mean number of young produced per colony as the response variable. Colony size per year was calculated as the number of nests active during the season. We included ten candidate models that included colony size, region and year (2006-2017) as a categorical variable. In all models there was a random effect for colony. The candidate models were: (1) Colony size * Region + Year, (2) Colony size + Region + Year, (3) Colony size * Region, (4) Colony size + Region, (5) Colony size + Year, (6) Region + Year, (7) Colony size, (8) Region, (9) Year, and (10) intercept only.

\section{Recruitment}

To test if local breeding performance contributed to changes in local population sizes via recruitment (i.e., addition of breeding pairs) we used model selection to examine if breeding productivity in year X predicted population growth rate. General linear mixed models were used to estimate the relationships for percentage point change in colony size from year $\mathrm{X}$ to year $\mathrm{X}+1$. Percentage point change in colony size was calculated as: [(colony size in year $\mathrm{X}+1 /$ mean colony size) - (colony size in year $\mathrm{X} /$ mean colony size)] $\mathrm{x}$ 100. Random effects for BBS stratum (transect of province/ territory and BCR) and colony were included in all models with colony nested in BBS stratum. Mean nest success and mean young produced at each colony per year was calculated and used as predictors in the models, and year (2006-2017) was included as a categorical variable. Predictor variables were from year $X$. The six candidate models were: (1) Mean nest success + Year, (2) Mean nest success, (3) Mean young produced + Year, (4) Mean young produced, (5) Year, and (6) intercept-only. 
We conducted all statistical analyses in $\mathrm{R}$ version 3.5.1 ( $\mathrm{R}$ Core Team 2018) using the glmmTMB (Brooks et al. 2017), lmerTest (Kuznetsova et al. 2017) and MuMIn (Barton 2018) packages. In all analyses, we used model selection based on small-sample Akaike Information Criterion (AICc; Burnham and Anderson 2002) and considered models with a $\Delta \mathrm{AICc}<2$ to be of equal importance. In all the analyses, we also centered and scaled (standardized) all continuous predictor variables.

\section{RESULTS}

\section{Barn Swallow BBS population growth rates and trends}

Irrespective of region in Canada, almost all Barn Swallow populations have declined since 1970. Barn Swallow population trends varied non-linearly with longitude across Canada. Longterm (1970 to 2018) annual population declines have been highest in western (British Columbia and Yukon) and eastern Canada (Quebec, Maritimes), and lowest in central Canada (Alberta, Saskatchewan, Manitoba; Fig. 1A). The average annual percent changes from 1970 to 2018 in the regions where our field sites were located were $-3.8 \%$ (British Columbia - BCR5), $-1.2 \%$ (Ontario - BCR13) and -4.8\% (New Brunswick - BCR14; Fig. A1.1).

Short-term (2009 to 2018) annual population declines were highest in the Boreal Softwood Shield (BCR 8) in Ontario $(-12.2 \%)$ and Quebec (-2.1\%), the Great Basin (BCR 9) in British Columbia (-1.4\%) and the Prairie Potholes (BCR 11) in Alberta (-1.0\%; Fig. 1B). The average annual percent changes from 2009 to 2018 in the regions where our field sites were located were $-0.1 \%$ (British Columbia - BCR5), - $0.8 \%$ (Ontario - BCR13) and $0.1 \%$ (New Brunswick - BCR14; Fig. A1.1). Across Canada the rates of decline appear to have been highest in the 1980s, 1990s, and 2000s (Fig. A1.2).

Recent estimated population sizes appear to be largest in the Prairie Provinces (strata in Alberta, Saskatchewan and Manitoba) and southern Ontario based on annual indices from BBS data (Fig. 1D). In 1970, the average annual index in the regions our field sites were located in were 21.3 (British Columbia - BCR5), 31.6 (Ontario - BCR13) and 27.2 (New Brunswick BCR14; Fig. 1C). In 2018, the only annual indices $>5$ in Canada were the Prairie Provinces, and the Lower Great Lakes/St. Lawrence Plain strata in southern Ontario and Quebec (Fig. 1D). In 2018, the average annual index in the regions where our field sites were located were 3.3 (British Columbia - BCR5), 17.7 (Ontario - BCR13), and 2.5 (New Brunswick - BCR14; Fig. 1D).

\section{Canada-wide breeding performance data}

There were 2685 nests monitored between 2013 and 2016 (1043 in British Columbia, 1371 in southwestern Ontario, and 271 in New Brunswick) that had the necessary information (i.e., clutch initiation date) for us to include in our analysis (Fig. 2). The nests were in 44 colonies (11 in British Columbia, 25 in southwestern Ontario, and 8 in New Brunswick) that were primarily barns. There was an average clutch size of $4.6 \pm 0.9$ ( \pm SD), an average brood size of $4.1 \pm 1.1$, an average nest success of $88.4 \% \pm 32.0 \%$ and an average number of young produced of $3.6 \pm 1.7$ (Fig. A1.7).

\section{Spatial and temporal effects on breeding performance}

Southwestern Ontario had the highest nest success (Fig. 3A) and number of young produced (Fig. 3B). Nest success was lowest in New Brunswick and number of young produced was lowest in British Columbia (Table A1.2).

Fig. 3. Relationships between mean Barn Swallow (Hirundo rustica) breeding performance (A - nest success, B - number of young produced) and year at study sites from 2013 to 2016. Data from southcentral Ontario in Bird Conservation Region 13 from 2014 to 2016 was excluded in this analysis. Error bars represent standard error.

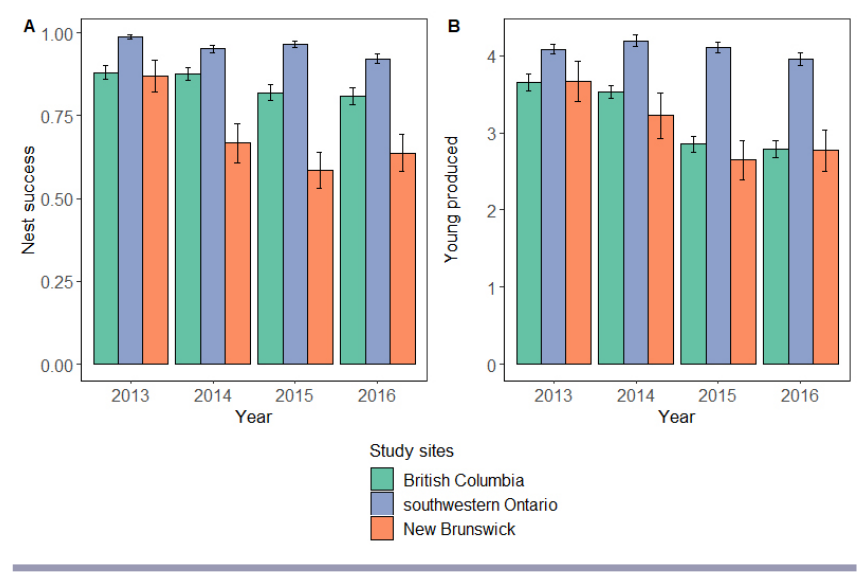

Although treated as a categorical variable, year had an effect on nest success and the number of young produced (Table A1.1, Table A1.2, Table A1.3). Nest success was lower in 2015 and 2016 compared to 2013 and 2014 (Table A1.2). The interaction between year and study region was significant in the top model for number of young produced (Table A1.1, Table A1.3). Specifically, the number of young produced was lower in British Columbia and New Brunswick in 2015 and 2016 compared to 2013 and 2014, while in southwestern Ontario this measure was consistent from 2013 to 2016 (Fig. 3B). There was a negative relationship between local breeding performance and clutch initiation date, meaning that nests started later in the season had lower rates of nest success, particularly in New Brunswick, and produced fewer young (Fig. A1.8, Table A1.2).

\section{Population indices and breeding performance}

Deviations from average annual indices were not related to average breeding performance or colony size at study sites in the subsequent year (Fig. 4, Table A1.4). The intercept-only model had a $\triangle \mathrm{AICc}=0$ in both model sets suggesting that average breeding performance does not predict regional population trends in the subsequent year.

\section{Density dependence}

Colony size ranged from 5 to 66 (SD: 18.5), 2 to 80 (14.1), and 6 to 33 (8.8) in British Columbia, Ontario, and New Brunswick, respectively. Local colony size in year $\mathrm{X}$ was a poor predictor of local breeding performance in year X (Fig. A1.9, Table A1.5, 
Fig. 4. Relationship between breeding performance and Barn Swallow (Hirundo rustica) Breeding Bird Survey (BBS) annual indices in year X+1 (A, B, C). Annual indices were calculated using a hierarchical Bayesian model with the first-difference approach on BBS data collected in the BBS strata (province/territory and Bird Conservation Region intersections) that encompass each field site. For each data point, the average breeding performance measure was linked to an annual index from the subsequent breeding period.

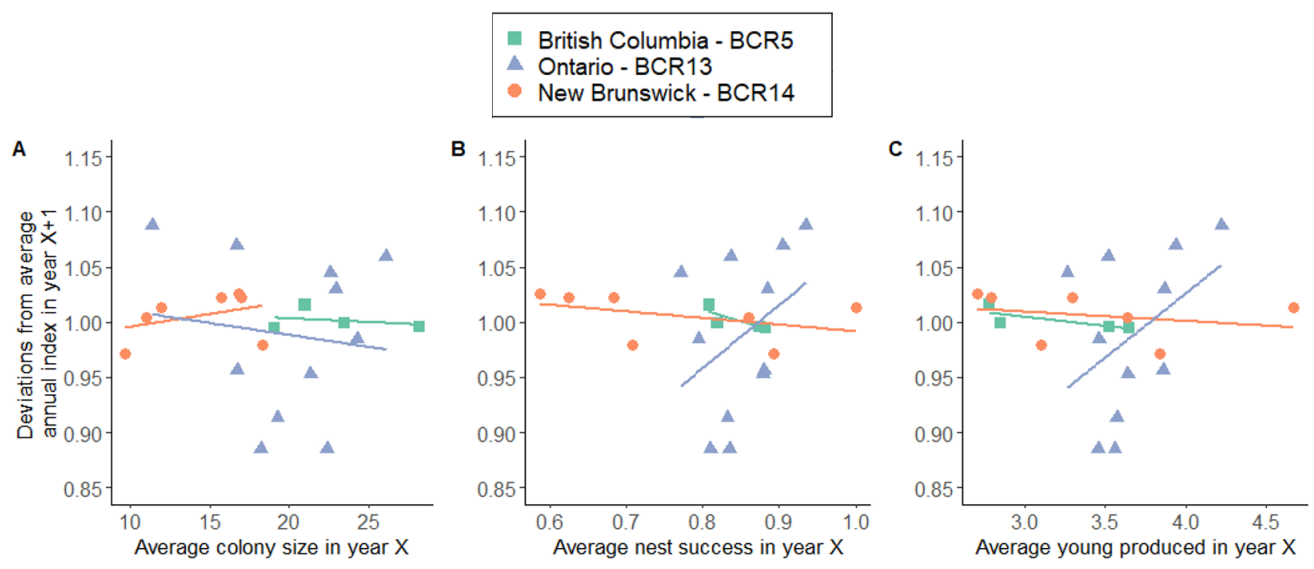

Table A1.6). However, for nest success, the interaction between colony size and region was a good predictor (Fig. A1.9A, Table A1.5). Specifically, there was a positive relationship between local colony size and local nest success in New Brunswick; the opposite direction than expected if density dependence was contributing to observed population growth rates (Fig. A1.9A, Table A1.6).

\section{Recruitment}

There was a positive relationship between local breeding performance in year $\mathrm{X}$ and percentage point change in local colony size from year $\mathrm{X}$ to year $\mathrm{X}+1$ (Fig. 5). The best performing model included mean young produced and year (Table A1.8, Table A1.9).

Fig. 5. Relationship between breeding performance (A - nest success, B - number of young produced) in year X and the percentage point (PP) difference in colony size from year $\mathrm{X}$ to year X+1 from 2006 to 2018 to test for recruitment.

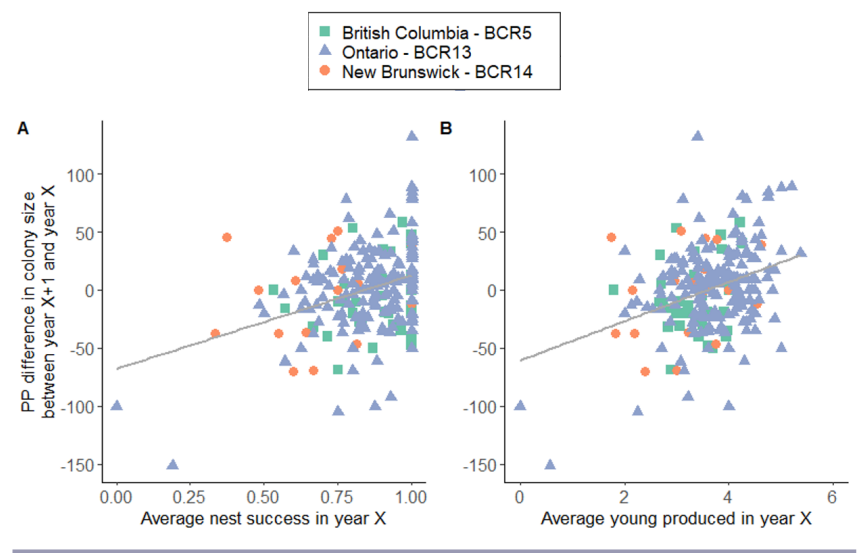

\section{DISCUSSION}

Our results show that Barn Swallows have undergone severe and prolonged population declines across Canada. However, the severity of declines varied across the country, with the strongest declines occurring in western and eastern Canada and the weakest declines occurring in the Prairie Provinces. Our results differ from Nebel et al. (2010) who found that Barn Swallow population declines followed a longitudinal gradient with the most severe declines in northeastern North America. This difference is likely related to differences in time periods and spatial extents examined by the studies. While Nebel et al. (2010) measured trends from 1966 to 2006, we examined 1970 to 2018, and while they focused on patterns across Canada and the United States, our focus was limited to Canada. Long-term population trends in Canada have been negative in all regions, while in the United States there have been positive, neutral, and negative trends depending on the region (Michel et al. 2016). Spatial patterning of Bank Swallow (Riparia riparia), Cliff Swallow (Petrochelidon pyrrhonota), and Tree Swallow (Tachycineta bicolor) long-term trends also suggests these species have had better outcomes in the Prairie Provinces compared to other regions in Canada (Fig. A1.10 to A1.12). Given these general patterns across species, we suggest that there may have been less predation and higher maintenance of suitable structures for Barn Swallow nesting in the Prairie Provinces. For example, in the Prairie Provinces, predator species richness is generally lower (DeGregorio et al. 2016). Another non-mutually exclusive hypothesis is that population-limiting factors operating outside of Canada may have differentially affected the western, central, and eastern populations where roosting, migratory, and wintering habitats are spatially distinct for these populations (Hobson et al. 2015). The latter could be examined by looking at historical changes in land use across the migration routes and wintering ranges with respect to BBS-derived regional population trends. 
Our research set out to look for a signal in breeding performance during what was assumed to be a period of widespread declines, but our analysis found that Barn Swallow populations were no longer strongly declining. Specifically, we found that short-term trends did not exhibit obvious spatial patterns and were generally weakly negative or neutral. That being said, Ontario - BCR13, the stratum our Ontario study area was located in, experienced a slight decline (-0.8\% annually). The $95 \%$ confidence interval (CI) around the annual indices from 2009 (17.8 to 23.0) and 2018 (16.4 to 20.8) have considerable overlap and it appears that there have been annual increasing and decreasing fluctuations in the estimates (Fig. A1.1D), so we argue that this is a relatively neutral trend. The Boreal Softwood Shield (BCR 8) in Ontario (-12.2\%) had the strongest negative short-term trend in Canada, but the annual index estimates were low from 2009 (0.13, 95\% CI: 0.04 to 0.40$)$ to $2018(0.04,95 \% \mathrm{CI}$ : $<0.01$ to 0.17$)$ and the BBS routes were limited to the southern portion of the stratum (GOC 2018) where a road network exists. Although, some negative trends are still occurring in strata in Canada, these trends can often be considered stable or are occurring in strata with small population sizes where there is uneven sampling coverage.

After long-term declines, Barn Swallow populations appear to have stabilized at low levels with relatively stable year-to-year colony sizes (Figure A1.13). Some reasons for this may be 1) BBS cannot track Barn Swallows as well at low population levels, 2) pockets of high-quality habitat remain, and/or 3) the factors that were causing reductions in population sizes are not acting anymore (e.g., alleviation of density-dependent effects associated with a possible reduction in aerial insect prey). To address the latter point, based on other studies it does not appear there was a single factor that acted evenly across the breeding grounds to cause broad-scale long-term aerial insectivores declines. Michel et al. (2016) found little spatial overlap in long-term population trajectories on the breeding grounds for five aerial insectivore species, including Barn Swallow, suggesting that non-breeding conditions more strongly contributed to observed declines. Barn Swallow populations winter in a broad geographic area, with low migratory connectivity between some breeding and wintering populations and essentially no connectivity between others (García-Pérez and Hobson 2014a, Hobson et al. 2015, Imlay et al. 2018). This suggests that widespread degradation of wintering ground habitat (Gaston and Fuller 2008, La Sorte et al. 2017), widespread wintering ground climatic changes (Paxton et al. 2014) and/or migration conditions (Hobson et al. 2015) may be responsible for long-term declines. Although Barn Swallow populations continue to be widespread and relatively stable at remaining high-quality sites, their lower overall abundance makes them vulnerable to factors that may cause future declines.

The lack of correlation between breeding performance at our local study sites and annual regional population change in each study region strongly cautions against extrapolating regional population trends from local-scale studies on a single demographic process. The most parsimonious explanation for our results is that breeding productivity at our study sites was not reflective of breeding productivity across the greater region in which they were situated. This is further supported, by our findings from the spatial and temporal effect on local breeding performance analysis that found our study site with the most negative short-term trend had the highest breeding performance measures, and our recruitment analysis that found a positive correlation between local breeding productivity in year $\mathrm{X}$ and local colony size in year $\mathrm{X}+1$. If this pattern were reflected in the broader region, then we should have observed a positive correlation between average breeding performance and regional population growth rates from the BBS, which we did not (see also Shutler et al. 2012). Regardless of the exact mechanism resulting in the lack of correlation between average breeding performance and regional population trends, given the very low return rate of juvenile Barn Swallows to their natal sites (Shields 1984), our results suggest that juveniles are recruiting from the local area, albeit, not the same colony. Similarly, Møller (1989) found that post-breeding population size in year $\mathrm{X}$ was positively related to the number of breeding pairs in year $X+1$ in a relatively local area in Denmark. Juvenile recruitment appears to be an important factor affecting local population growth in Barn Swallows, but the link between regional breeding performance and estimated population trajectories is ambiguous.

When considering local colony size and reproductive performance in the same year to examine density-dependent effects, we did not find a negative relationship as some studies have found (Shields and Crook 1987), suggesting that Barn Swallow populations in Canada are below carrying capacity and are not currently experiencing food limitations. Consistent with this finding, studies conducted at our field sites did not find a link between breeding performance measures and local breeding ground factors in terms of land use. For example, at the southwestern Ontario and British Columbia field sites, farming intensity surrounding the colonies had no effect on breeding performance measures (Boynton 2017, Kusack et al. 2020), and no link was found between breeding performance measures and measures of prey availability at the southcentral Ontario field site in 2015 and 2016 (McClenaghan et al. 2019) and New Brunswick field site in 2014 and 2015 (Imlay et al. 2017). Although we did not find evidence of density dependence, prey availability during the nesting season is important. Timing of reproduction, likely through correlations with average peak prey availability, can affect both nestling quality and nesting success in Barn Swallows (Ambrosini et al. 2006, Kusack et al. 2020). Furthermore, if food availability is limiting, adults may trade-off their own survival with that of their nestlings (Imlay et al. 2017, although see Mitchell et al. 2012), and availability of quality food (e.g., aquatic insects) may be more important than the quantity of food available (Twining et al. 2016, Twining et al. 2018, Génier et al. 2021). We assume that Barn Swallows benefit from living in colonies beyond measured breeding performance, for instance, a study on Cliff Swallows found that the probability of daily survival increased with colony size (Brown and Brown 2004). In particular, the Barn Swallows in New Brunswick may benefit from living in colonies, as we found a positive relationship between colony size and nest success at the study sites in that region. We suggest that timing of reproduction is likely affected by carryover effects from the wintering grounds or migration routes (Rioux Paquette et al. 2014, Imlay et al. 2019) and by weather conditions experienced on the breeding grounds (Saino et al. 2004).

Local colony reproductive performance had a positive relationship with change in local colony size from one year to the next, again, suggesting that density-dependent effects associated 
with food limitation are not currently occurring on the breeding grounds. Given the very low return rate of juveniles to their natal sites (Shields 1984), including juveniles in this study (Boynton et al. 2020, Evans et al. 2020), this result suggests that juveniles are recruiting from the same region, but not the same colony. Although local reproductive performance predicted changes in local colony size, the relationship had high variability. Postfledging survival on the breeding grounds (Boynton et al. 2020, Evans et al. 2020) and on the non-breeding grounds could account for some of the variation we observed. Post-fledging survival was 44\% (after three weeks) averaged across 2015 and 2016 in British Columbia (Boynton et al. 2020) and 42\% (after eight weeks) averaged across 2016 and 2017 in southwestern Ontario (Evans et al. 2020). These post-fledging survival rates are considered low compared to other species with northern breeding ranges (Lloyd and Martin 2016). Based on the number of unbanded birds observed at the colonies each year, juveniles seldom return to their natal colonies, so we were unable to examine juvenile survival after one year to make inferences about rates of post-fledging survival on the non-breeding grounds.

We acknowledge that there are limitations in our ability to relate average reproductive performance to BBS annual index estimates. The power of our analysis was low (similar to Shutler et al. 2012) because at each field site an average reproductive performance measure or colony size was calculated for each year, resulting in only 22 data points. Collecting more years of nesting data would give our analysis more power, but other approaches using existing data may be more beneficial. An integrated population model, that considers the full scope of population dynamics beyond reproductive performance, could provide insights on population growth limitations. For example, using this approach a study on Barn Swallows in Switzerland found strong impacts of adult survival and immigration on growth rates (Schaub et al. 2015), two measures our analysis does not directly account for. Another consideration is that BBS surveys may give accurate overall trends for Barn Swallows, but fine-scale changes in regional breeding ground abundance may not be accurately estimated for colonial species, like Barn Swallow (COSEWIC 2011).

\section{CONCLUSION}

Broad-scale long-term monitoring programs, such as BBS, show that Barn Swallow populations have declined dramatically across the country and that these declines are strongest in the eastern and western parts of Canada. Our analysis of the BBS data found that short-term trends in Barn Swallow populations are no longer clearly negative, as populations across most regions of Canada appear to have stabilized at low abundances. Importantly, localscale reproductive measures from study sites across Canada did not predict regional population changes in the same regions, suggesting we should not extrapolate from local-scale studies on a single demographic process to broader populations. The lack of evidence for density-dependent effects suggests that Barn Swallow populations in Canada are likely below carrying capacity and are unlikely to be experiencing food limitation currently. However, this does not preclude that food limitation on the breeding grounds was at least partly responsible for past population declines. We found that colony sizes were fairly stable and local reproductive performance had a positive effect on local colony sizes the following year, suggesting that young are successfully recruited into the population and providing further evidence that populations are below carrying capacity. While this latter result suggests that factors affecting reproduction may play a role in population recovery, the relative importance of factors operating on the wintering grounds, during migration, or on the breeding grounds in terms of population size limitations requires further study. Factors affecting current population changes may not have been those that were acting historically.

Responses to this article can be read online at: https://www.ace-eco.org/issues/responses.php/1933

\section{Acknowledgments:}

We thank all field staff and volunteers that collected the reproductive performance data and the volunteers that collect data for the BBS. Special thanks to the landowners who gave permission for their buildings to be accessed for the Barn Swallow breeding performance data collection without whom this research would not have been possible. Funding: This work was supported by Environment and Climate Change Canada.

\section{LITERATURE CITED}

Ambrosini, R., A. M. Bolzern, L. Canova, S. Arieni, A. P. Møller, and N. Saino. 2002. The distribution and colony size of Barn Swallows in relation to agricultural land use. Journal of Applied Ecology 39:524-534. https://doi.org/10.1046/j.1365-2664.2002.00721. $\mathrm{x}$

Ambrosini, R., R. P. Ferrari, R. Martinelli, M. Romano, and N. Saino. 2006. Seasonal, meteorological, and microhabitat effects on breeding success and offspring phenotype in the barn swallow, Hirundo rustica. Ecoscience, 13:298-307. https://doi.org/10.2980/ i1 195-6860-13-3-298.1

Barton, K. 2018. MuMIn: Multi-Model Inference. R package version 1.42.1. [online] URL: https://CRAN.R-project.org/ package $=$ MuMIn [cited 2019 Oct]

Billeter, R., J. Liira, D. Bailey, R. Bugter, P. Arens, I. Augenstein, S. Aviron, J. Baudry, R. Bukacek, F. Burel, M. Cerny, G. De Blust, R. De Cock, T. Diekötter, H. Dietz, J. Dirksen, C. Dormann, W. Durka, M. Frenzel, R. Hamersky, F. Hendrickx, F. Herzog, S. Klotz, B. Koolstra, A. Lausch, D. Le Coeur, J. Maelfait, P. Opdam, M. Roubalova, A. Schermann, N. Schermann, T. Schmidt, O. Schweiger, M. Smulders, M. Speelmans, P. Simova, J. Verboom, W. van Wingerden, M. Zobel, and P. Edwards. 2008. Indicators for biodiversity in agricultural landscapes: a panEuropean study. Journal of Applied Ecology 45:141-150. https:// doi.org/10.1111/j.1365-2664.2007.01393.x

Boynton, C. K. 2017. Breeding productivity, phenology and habitat use of two co-occurring aerial insectivores. Thesis, Simon Fraser University, Burnaby, Canada. 
Boynton, C. K., N. A. Mahony, and T. D. Williams. 2020. Barn Swallow (Hirundo rustica) fledglings use crop habitat more frequently in relation to its availability than pasture and other habitat types. The Condor: Ornithological Applications 122: duz067. https://doi.org/10.1093/condor/duz067

Brooks, M. E., K. Kristensen, K. J. van Benthem, A. Magnusson, C. W. Berg, A. Nielsen, H. J. Skaug, M. Maechler, and B. M. Bolker. 2017. glmmTMB Balances Speed and Flexibility Among Packages for Zero-inflated Generalized Linear Mixed Modeling. The R Journal 9:378-400. https://doi.org/10.32614/RJ-2017-066

Brown, C. R., and M. B. Brown. 2004. Group size and ectoparasitism affect daily survival probability in a colonial bird. Behavioral Ecology and Sociobiology 56:498-511. https://doi. org/10.1007/s00265-004-0813-6

Brown, M. B., and C. R. Brown. 2019. Barn Swallow (Hirundo rustica), version 2.0. in Rodewald, P G, editor. The Birds of North America. Cornell Lab of Ornithology, Ithaca, NY, USA. https:// doi.org/10.2173/bna.barswa.02

Burnham, K. P., and D. R. Anderson. 2002. Model selection and multimodel inference: a practical information-theoretic approach. Second edition. Springer-Verlag, New York, New York, USA.

Caswell, H. 2000. Prospective and retrospective perturbation analyses: their roles in conservation biology. Ecology 81:619-627. https://doi.org/10.2307/177364

COSEWIC. 2011. COSEWIC assessment and status report on the Barn Swallow Hirundo rustica in Canada. Committee on the Status of Endangered Wildlife in Canada, Ottawa, Canada. 37 pages.

DeGregorio, B. A., S. J. Chiavacci, T. J. Benson, J. H. Sperry, and P. J. Weatherhead. 2016. Nest predators of North American birds: continental patterns and implications. BioScience 66:655-665. https://doi.org/10.1093/biosci/biw071

Evans, D. R., K. A. Hobson, J. W. Kusack, M. D. Cadman, C. M. Falconer, and G. W. Mitchell. 2020. Individual condition, but not fledging phenology, carries over to affect post-fledging survival in a Neotropical migratory songbird. Ibis 162:331-344. https://doi.org/10.1111/ibi.12727

Evans, K. L., J. D. Wilson, and R. B. Bradbury. 2007. Effects of crop type and aerial invertebrate abundance on foraging barn swallows Hirundo rustica. Agriculture, Ecosystems and Environment 122:267-273. https://doi.org/10.1016/j.agee.2007.01.015

García-Pérez, B., and K. A. Hobson. 2014a. A multi-isotope $(\mathrm{d} 2 \mathrm{H}, \mathrm{d} 13 \mathrm{C}, \mathrm{d} 15 \mathrm{~N})$ approach to establishing migratory connectivity of Barn Swallow (Hirundo rustica). Ecosphere 5:1-12. https://doi.org/10.1890/ES13-00116.1

García-Pérez, B., K. A. Hobson, G. Albrecht, M. D. Cadman, and A. Salvadori. 2014b. Influence of climate on annual survival of Barn Swallows (Hirundo rustica) breeding in North America. The Auk 131:351-362. https://doi.org/10.1642/AUK-13-145.1
Gaston, K. J., and R. A. Fuller. 2008. Commonness, population depletion and conservation biology. Trends in Ecology \& Evolution 23:14-9. https://doi.org/10.1016/j.tree.2007.11.001

Génier, C. S. V., C. G. Guglielmo, G. W. Mitchell, M. Falconer, and K. A. Hobson. 2021. Nutritional consequences of breeding away from riparian habitats in Bank Swallows: New evidence from multiple endogenous markers. Conservation Physiology, in press. https://doi.org/10.1093/conphys/coaa140

Government of Canada (GOC). 2018. Breeding Bird Survey routes in Canada. Government of Canada, Canada. [online] URL: https://www.canada.ca/en/environment-climate-change/ services/bird-surveys/landbird/north-american-breeding/routes.html\#toc0. [cited $2020 \mathrm{Mar}]$

Government of Canada (GOC). 2019. Breeding Bird Survey statistical methods. Government of Canada, Canada. [online] URL: https://wildlife-species.canada.ca/breeding-bird-surveyresults/P006/A001/?lang=e/. [cited 2019 Oct]

Hallmann, C. A., R. P. B. Foppen, C. A. M. van Turnhout, H. de Kroon, and E. Jongejans. 2014. Declines in insectivorous birds are associated with high neonicotinoid concentrations. Nature 511:341-3. https://doi.org/10.1038/nature13531

Hansen, M. C., P. V. Potapov, R. Moore, M. Hancher, S. Turubanova, A. Tyukavina, D. Thau, S. Stehman, S. Goetz, T. R. Loveland, A. Kommareddy, A. Egorov, L. Chini, C. O. Justice and J. R. G. Townshend. 2013. High-resolution global maps of 21 st-century forest cover change. Science 342:850-853. https://doi. org/10.1126/science. 1244693

Hobson, K. A., K. J. Kardynal, S. L. Van Wilgenburg, G. Albrecht, A. Salvadori, M. D. Cadman, F. Liechti, and J. W. Fox. 2015. A continent-wide migratory divide in North American breeding Barn Swallows (Hirundo rustica). PLoS ONE 10: e0129340. https://doi.org/10.1371/journal.pone.0129340

Imlay, T. L., F. Angelier, K. A. Hobson, G. Mastromonaco, S. Saldanha, and M. L. Leonard. 2019. Multiple intrinsic markers identify carry-over effects from wintering to breeding sites for three Nearctic-Neotropical migrant swallows. The Auk 136: ukz053. https://doi.org/10.1093/auk/ukz053

Imlay, T. L., K. A. Hobson, A. Roberto-Charron, and M. L. Leonard. 2018. Wintering areas, migratory connectivity and habitat fidelity of three declining nearctic-neotropical migrant swallows. Animal Migration 5:1-16. https://doi.org/10.1515/ ami-2018-0001

Imlay, T. L., H. A. R. Mann, and M. L. Leonard. 2017. No effect of insect abundance on nestling survival or mass for three aerial insectivores. Avian Conservation and Ecology 12(2):19. https:// doi.org/10.5751/ACE-01092-120219

Kusack, J. W., G. W. Mitchell, D. R. Evans, M. D. Cadman, and K. A. Hobson. 2020. Effects of agricultural intensification on nestling condition and number of young fledged of barn swallows (Hirundo rustica). Science of the Total Environment 709:136195. https://doi.org/10.1016/j.scitotenv.2019.136195 
Kuznetsova, A., P. B. Brockhoff, and R. H. B. Christensen. 2017. lmerTest package: tests in linear mixed effects models. Journal of Statistical Software 82:1-26. https://doi.org/10.18637/jss.v082.i13

La Sorte, F. A., D. Fink, P. J. Blancher, A. D. Rodewald, V. RuizGutierrez, K. V. Rosenberg, W. M. Hochachka, P. H. Verburg, and S. Kelling. 2017. Global change and the distributional dynamics of migratory bird populations wintering in Central America. Global Change Biology 23:5284-5296. https://doi. org/10.1111/gcb.13794

Laurance, W. F., J. Sayer, and K. G. Cassman. 2014. Agricultural expansion and its impacts on tropical nature. Trends in Ecology \& Evolution 29:107-116. https://doi.org/10.1016/j.tree.2013.12.001

Link, W. A., J. R. Sauer, and D. K. Niven. 2017. Model selection for the North American Breeding Bird Survey: A comparison of methods. The Condor: Ornithological Applications 119:546-547. https://doi.org/10.1650/CONDOR-17-1.1

Lloyd, P., and T. E. Martin. 2016. Fledgling survival increases with development time and adult survival across north and south temperate zones. Ibis 158:135-143. https://doi.org/10.1111/ ibi. 12325

McClenaghan, B., K. C. R. Kerr, and E. Nol. 2019. Does prey availability affect the reproductive performance of Barn Swallows, Hirundo rustica, breeding in Ontario, Canada? Canadian Journal of Zoology 97:979-987. https://doi. org/10.1139/cjz-2019-0001

McNew, L. B., A. J. Gregory, S. M. Wisely, and B. K. Sandercock. 2012. Demography of greater prairie-chickens: regional variation in vital rates, sensitivity values, and population dynamics. The Journal of Wildlife Management 76:987-1000. https://doi. org/10.1002/jwmg.369

Michel, N. L., A. C. Smith, R. G. Clark, C. A. Morrissey, and K. A. Hobson. 2016. Differences in spatial synchrony and interspecific concordance inform guild-level population trends for aerial insectivorous birds. Ecography 39:774-786. https://doi. org/10.1111/ecog.01798

Mitchell, G. W., N. T. Wheelwright, C. G. Guglielmo, and D. R. Norris. 2012. Short-and long-term costs of reproduction in a migratory songbird. Ibis 154:325-337. https://doi.org/10.1111/ j.1474-919X.2012.01212.x

Møller, A. P. 1987. Intraspecific nest parasitism and anti-parasite behaviour in swallows, Hirundo rustica. Animal Behaviour 35:247-254. https://doi.org/10.1016/S0003-3472(87)80230-0

Møller, A. P. 1989. Population dynamics of a declining swallow Hirundo rustica population. Journal of Applied Ecology 58:1051-1063. https://doi.org/10.2307/5141

Nebel, S., A. Mills, J. McCracken, and P. Taylor. 2010. Declines of aerial insectivores in North America follow a geographic gradient. Avian Conservation and Ecology 5(2):1. https://doi. org/10.5751/ACE-00391-050201

Noon, B. R., and Sauer, J.R., 1992. Population models for passerine birds: structure, parameterization, and analysis. In
Wildlife 2001: populations (pp. 441-464). Springer, Dordrecht. https://doi.org/10.1007/978-94-011-2868-1_34

North American Bird Conservation Initiative (NABCI) Canada. 2019. The state of Canada's birds, 2019. Environment Canada, Ottawa, Ontario, Canada. 12 pages.

Paxton, K. L., E. B. Cohen, E. H. Paxton, Z. Németh, and F. R. Moore. 2014. El Niño-Southern Oscillation is linked to decreased energetic condition in long-distance migrants. PLoS ONE 9: e95383. https://doi.org/10.1371/journal.pone.0095383

R Core Team. 2018. R: A language and environment for statistical computing. R Foundation for Statistical Computing, Vienna, Austria.

Rioux Paquette, S., F. Pelletier, D. Garant, and M. Bélisle. 2014. Severe recent decrease of adult body mass in a declining insectivorous bird population. Proceedings of the Royal Society B: Biological Sciences 281:20140649. https://doi.org/10.1098/ rspb.2014.0649

Sæther, B.-E., and Ø. Bakke. 2000. Avian life history variation and contribution of demographic traits to the population growth rate. Ecology 81:642-653. https://doi.org/10.1890/0012-9658 (2000)081[0642:ALHVAC]2.0.CO;2

Saino, N., M. Romano, R. Ambrosini, R. P. Ferrari, A. P. Møller. 2004. Timing of reproduction and egg quality covary with temperature in the insectivorous Barn Swallow, Hirundo rustica. Functional Ecology 18:50-57. https://doi.org/10.1046/ j.0269-8463.2004.00808.x

Sauer, J. R., K. L. Pardieck, D. J. Ziolkowski Jr, A. C. Smith, M.A. R. Hudson, V. Rodriguez, H. Berlanga, D. K. Niven, and W. A. Link. 2017. The first 50 years of the North American Breeding Bird Survey. The Condor: Ornithological Applications 119:576-593. https://doi.org/10.1650/CONDOR-17-83.1

Schaub, M., J. von Hirschheydt, and M. U. Grüebler. 2015. Differential contribution of demographic rate synchrony to population synchrony in barn swallows. Journal of Animal Ecology 84:1530-1541. https://doi.org/10.1111/1365-2656.12423

Shields, W. M. 1984. Factors affecting nest and site fidelity in Adirondack Barn Swallows (Hirundo rustica). The Auk 101:780-789. https://doi.org/10.2307/4086904

Shields, W. M., and J. R. Crook. 1987. Barn swallow coloniality: a net cost for group breeding in the Adirondacks? Ecology 68:1373-1386. https://doi.org/10.2307/1939221

Sherry, T. W., and R. T. Holmes. 1995. Summer versus winter limitation of populations: what are the issues and what is the evidence. Pages 85-120 in Martin, T. E. and D. M. Finch, editors Ecology and management of neotropical migratory birds. Oxford University Press, New York, New York, USA.

Shutler, D., D. J. Hussell, D. Norris, D. W. Winkler, F. Bonier, M. Belisle, R. G. Clark, R. D. Dawson, N. T. Wheelwright, M. P. Lombardo, P. A. Thorpe, M. A. Truan, R. Walsh, M. L. Leonard, A. G. Horn, C. M. Vleck, D. Vleck, A. P. Rose, L. A. Wittingham, P. O. Dunn, K. A. Hobson, and M. T. Stanback. 2012. Spatiotemporal patterns in nest box occupancy by tree swallows 
across North America. Avian Conservation and Ecology 7(1):3. http://doi.org/10.5751/ACE-00517-070103

Siriwardena, G. M., S. R. Baillie, H. Q. Crick, and J.D. Wilson. 2000. The importance of variation in the breeding performance of seed-eating birds in determining their population trends on farmland. Journal of Applied Ecology, 37:128-148. https://doi. org/10.1046/j.1365-2664.2000.00484.x

Smith, A. C., and B. P. M. Edwards. 2020. North American Breeding Bird Survey status and trend estimates to inform a widerange of conservation needs, using a flexible Bayesian hierarchical generalized additive model. The Condor: Ornithological Applications 123:duaa065. https://doi.org/10.1093/ornithapp/ duaa065

Species at Risk Act (SARA) Registry. 2019. Species at risk public registry. [online] URL: https://www.canada.ca/en/environmentclimate-change/services/species-risk-public-registry.html [cited 2019 Oct]

Spiller, K. J., and R. Dettmers. 2019. Evidence for multiple drivers of aerial insectivore declines in North America. The Condor: Ornithological Applications 121:duz010. https://doi.org/10.1093/ condor/duz010

Stanton, R., C. Morrissey, and R. Clark. 2018. Analysis of trends and agricultural drivers of farmland bird declines in North America: A review. Agriculture, Ecosystems and Environment 254:244-254. https://doi.org/10.1016/j.agee.2017.11.028

Taylor, L. U., B. K. Woodworth, B. K. Sandercock, and N. T. Wheelwright. 2018. Demographic drivers of collapse in an island population of Tree Swallows. The Condor: Ornithological Applications 120:828-841. https://doi.org/10.1650/CONDOR-18-75.1

Twining, C. W., J. T. Brenna, P. Lawrence, J. R. Shipley, T. N. Tollefson, and D. W. Winkler. 2016. Omega-3 long-chain polyunsaturated fatty acids support aerial insectivore performance more than food quantity. Proceedings of the National Academy of Sciences 113:10920-10925. https://doi. org/10.1073/pnas.1603998113

Twining, C. W., J. R. Shipley, and D. W. Winkler. 2018. Aquatic insects rich in omega-3 fatty acids drive breeding success in a widespread bird. Ecology letters 21:1812-1820. https://doi. org/10.1111/ele.13156

Weegman, M. D., S. Bearhop, A. D. Fox, G. M. Hilton, A. J. Walsh, J. L. McDonald, and D. J. Hodgson. 2016. Integrated population modelling reveals a perceived source to be a cryptic sink. Journal of Animal Ecology 85:467-475. https://doi. org/10.1111/1365-2656.12481

Weiser, E. L., R. B. Lanctot, S. C. Brown, H. Gates, J. Bêty, M. L. Boldenow, R. W. Brook, G. S. Brown, W. B. English, S. A.
Flemming, S. E. Franks, H. G. Gilchrist, M.-A. Giroux, A. Johnson, S. Kendall, L. V. Kennedy, L. Koloski, E. Kwon, J.-F. Lamarre, D. B. Lank, C. J. Latty, N. Lecomte, J. R. Liebezeit, R. L. McGuire, L. McKinnon, E. Nol, D. Payer, J. Perz, J. Rausch, M. Robards, S. T. Saalfeld, N. R. Senner, P. A. Smith, M. Soloviev, D. Solovyeva, D. H. Ward, P. F. Woodard, and B. K. Sandercock. 2020. Annual adult survival drives trends in Arctic-breeding shorebirds but knowledge gaps in other vital rates remain. The Condor: Ornithological Applications 122:duaa026. https://doi. org/10.1093/condor/duaa026

Wisdom, M. J., L. S. Mills, and D. F. Doak. 2000. Life stage simulation analysis: estimating vital-rate effects on population growth for conservation. Ecology 81:628-641. https://doi. org/10.1890/0012-9658(2000)081[0628:LSSAEV]2.0.CO;2

Wilson, S., J. F. Saracco, R. Krikun, D. T. Flockhart, C. M. Godwin, and K. R. Foster. 2018. Drivers of demographic decline across the annual cycle of a threatened migratory bird. Scientific Reports 8:7316. https://doi.org/10.1038/s41598-018-25633-z

Zipkin, E. F., and S. P. Saunders. 2018. Synthesizing multiple data types for biological conservation using integrated population models. Biological Conservation 217:240-250. https://doi. org/10.1016/j.biocon.2017.10.017
Editor-in-Chief: Alexander L.Bond Subject Editor: Philip D.Taylor

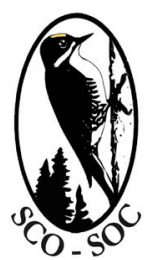

Sponsored by the Society of Canadian Ornithologists and Birds Canada

Parrainée par la Société des ornithologistes du Canada et Oiseaux Canada 
Appendix 1. Supplementary figures and tables
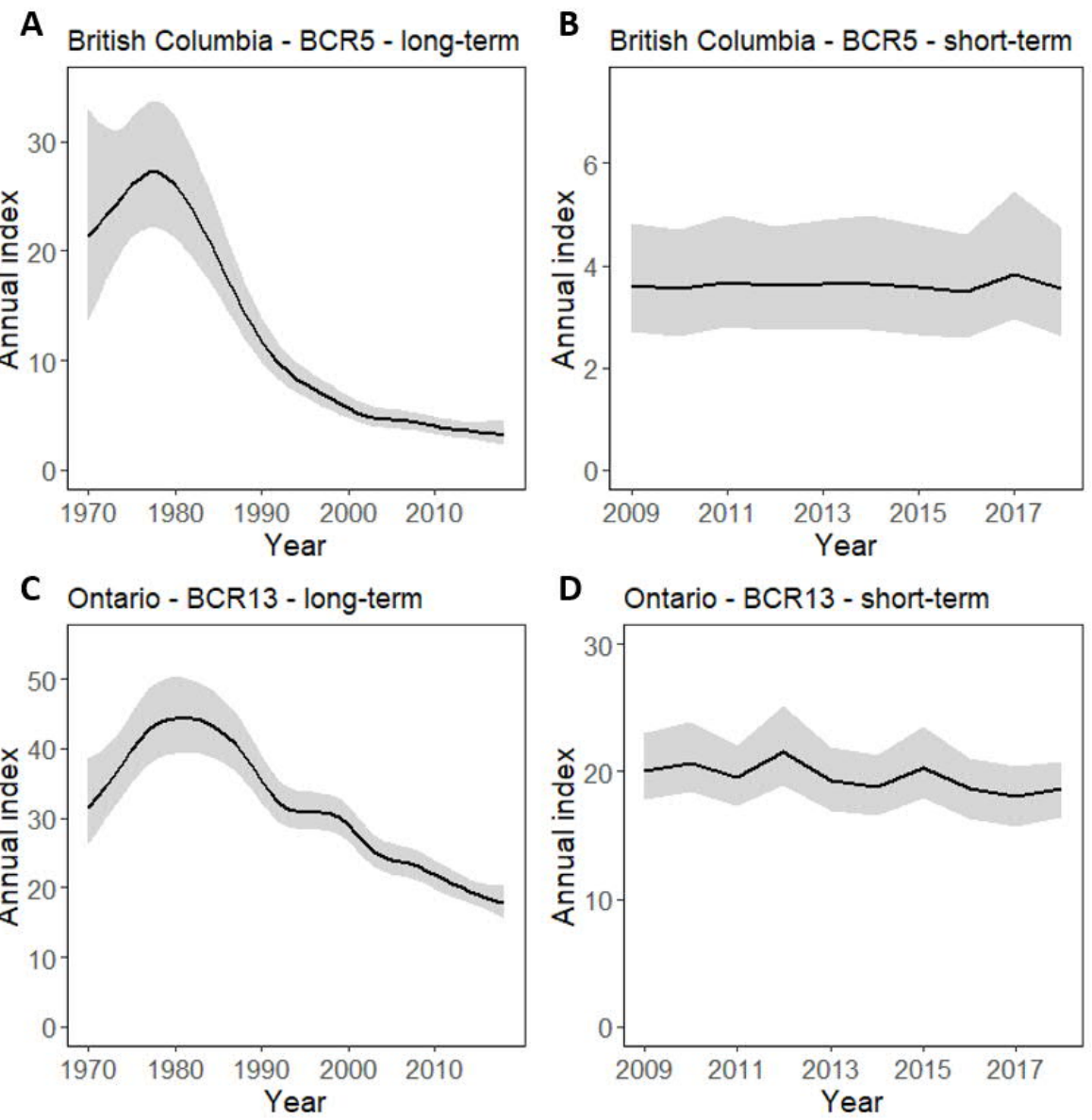

D Ontario - BCR13 - short-term

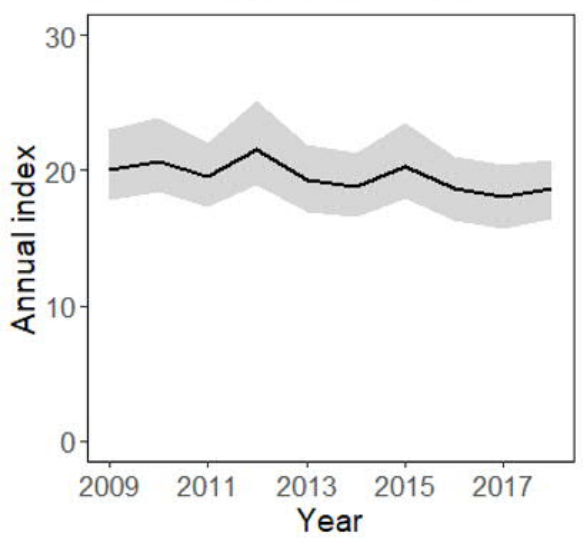

E New Brunswick - BCR14 - long-term

F New Brunswick - BCR14 - short-term
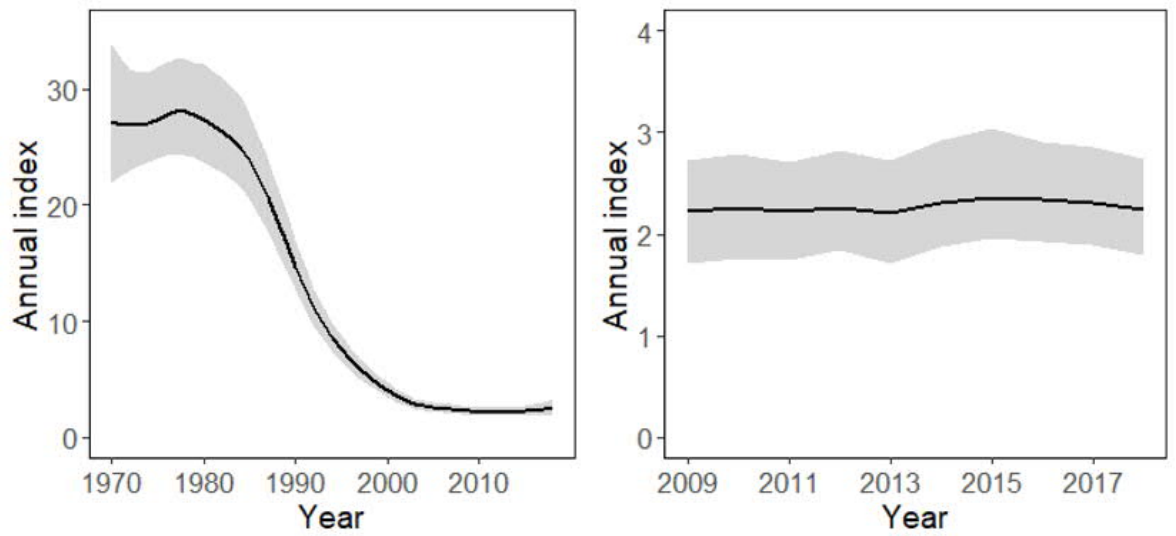

Figure A1.1. Annual indices of Barn Swallows in three BBS strata, British Columbia - BCR5 (A, B), Ontario - BCR13 (C, D) and New Brunswick - BCR14 (E, F), where breeding performance was studied. Long-term and short-term estimates of annual indices are from 1970 to 2018 (A, C, E) and 2009 to 2018 (B, D, F), respectively. Annual indices were calculated using a hierarchical Bayesian model with the GAM approach for 1970 to 2018 and the slope approach for 2009 to 2018. 

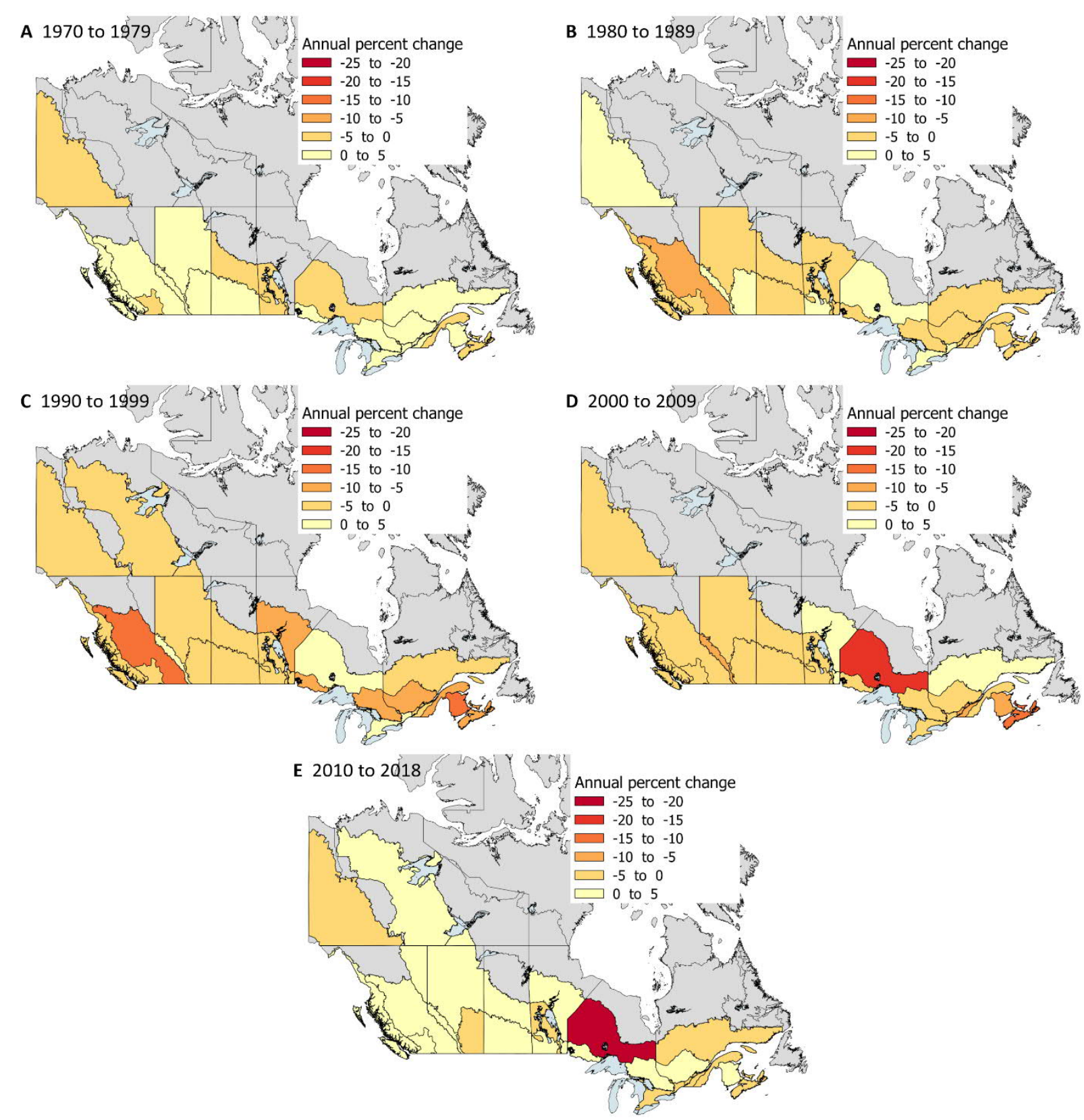

Figure A1.2. Average annual percent change in the Barn Swallow population in Canada from (A) 1970 to 1979, (B) 1980 to 1989, (C) 1990 to 1999, (D) 2000 to 2009 and (E) 2010 to 2018 stratified by intersections of province/territory region and BCR. The population trends use annual index data that represents the estimated average abundance of Barn Swallows on BBS routes run in a given year by an average observer in that stratum. The annual indices were calculated using hierarchical Bayesian models using the slope approach. In the model, we extracted the annual indices for the time periods indicated in each panel and chose the slope approach because of the constant rate of change assumption. Barn Swallows either are not present or have insufficient data in regions shaded gray. 


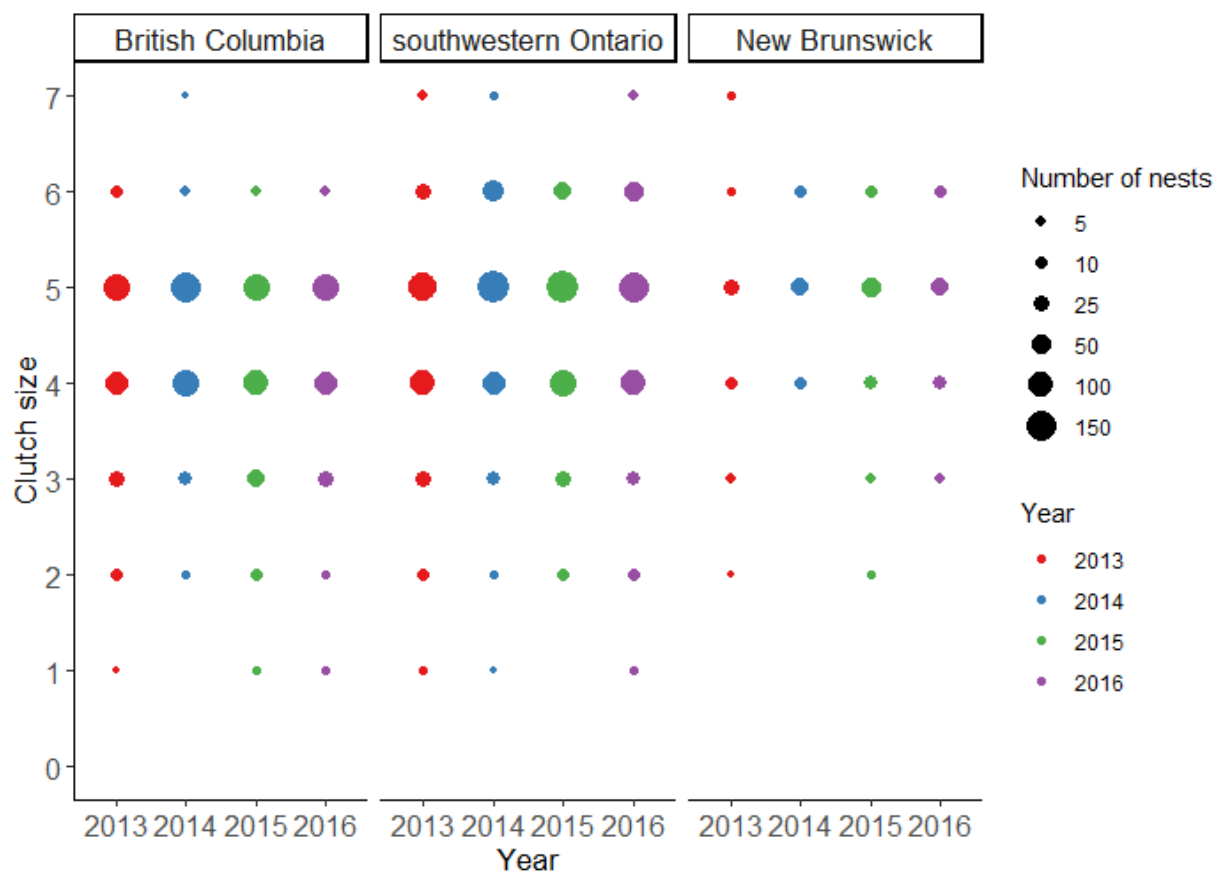

Figure A1.3. Number of nests organized by year, clutch size (number of eggs) and study region (BC, southwestern Ontario and New Brunswick). 


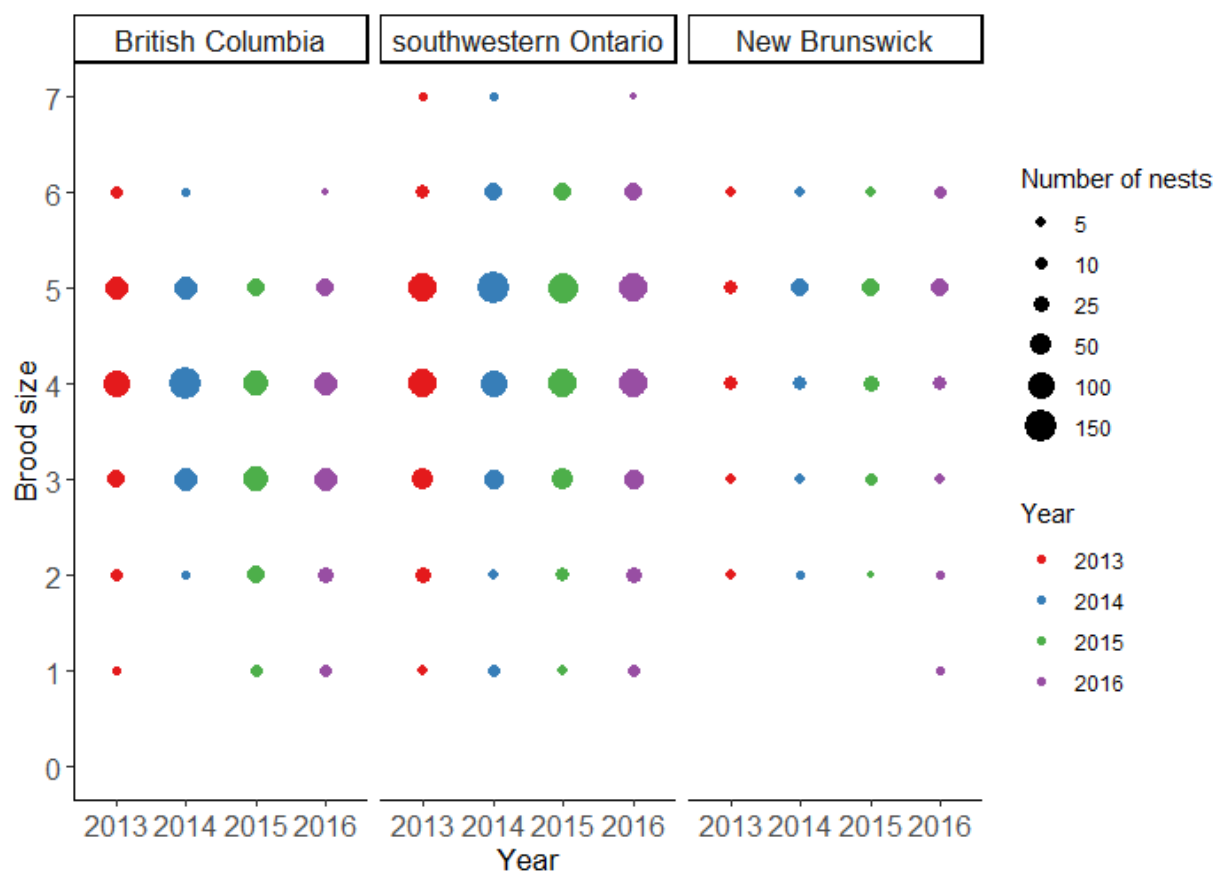

Figure A1.4. Number of nests organized by year, brood size (number of nestlings) and study region (BC, southwestern Ontario and New Brunswick). 


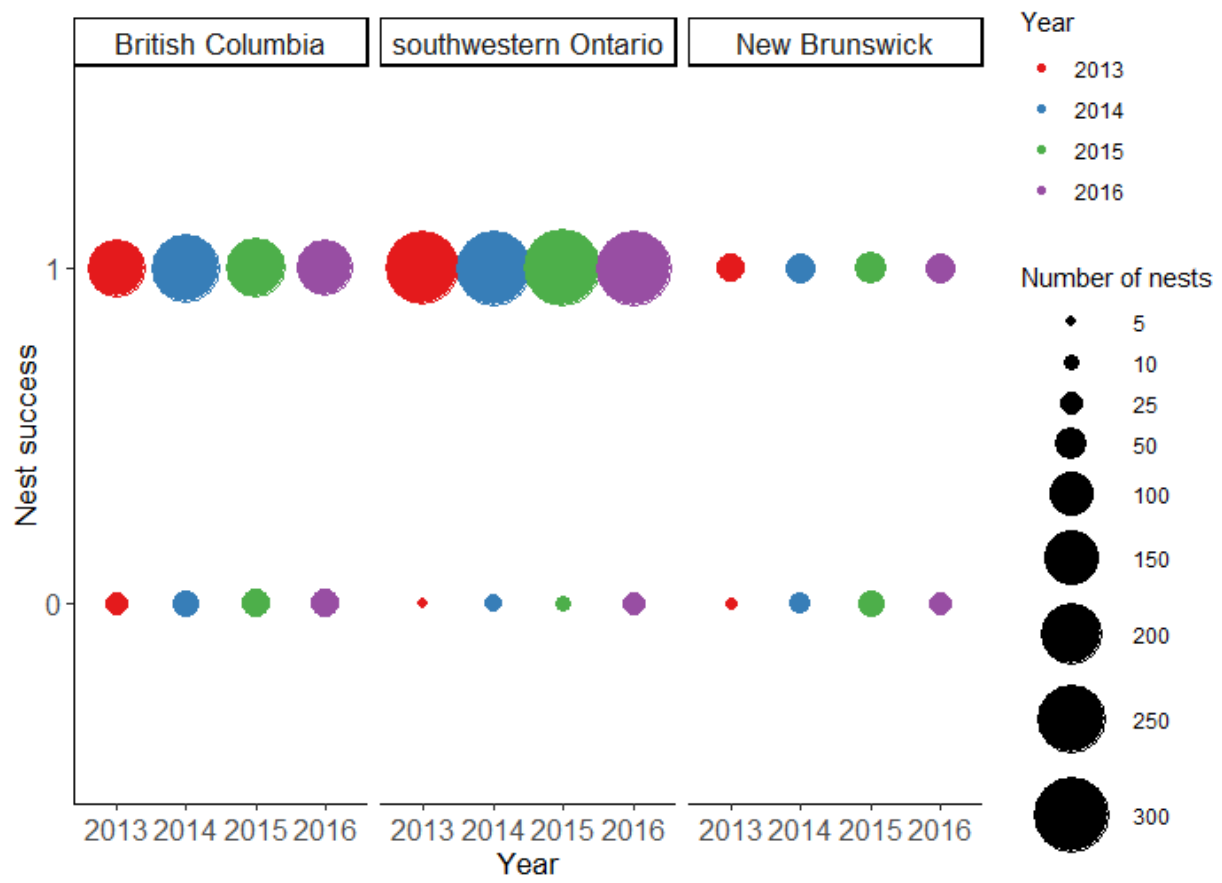

Figure A1.5. Number of successful (1) and unsuccessful (0) nests organized by year and study region (BC, southwestern Ontario and New Brunswick). 


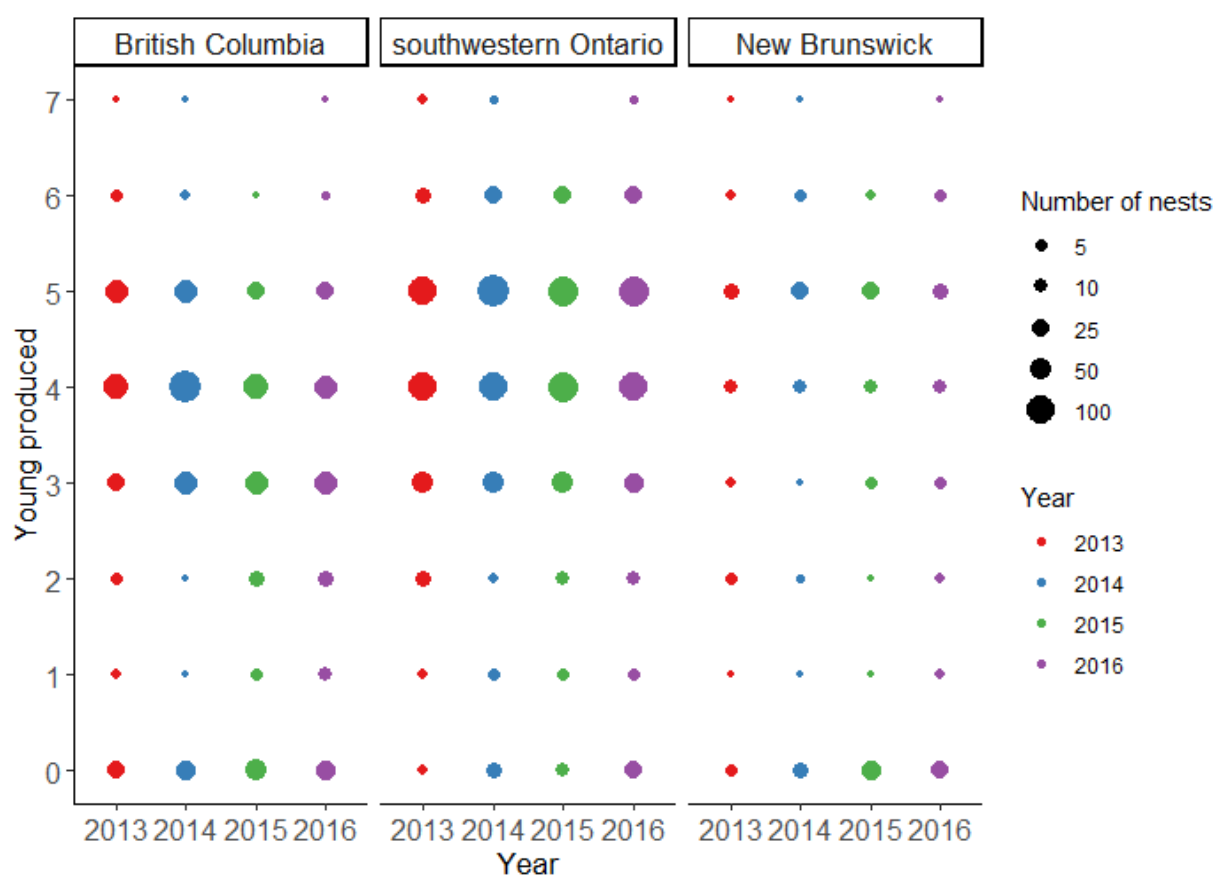

Figure A1.6. Number of nests organized by year, number of young produced (brood size multiplied by nest success for a individual nest) and study region (BC, southwestern Ontario and New Brunswick). 

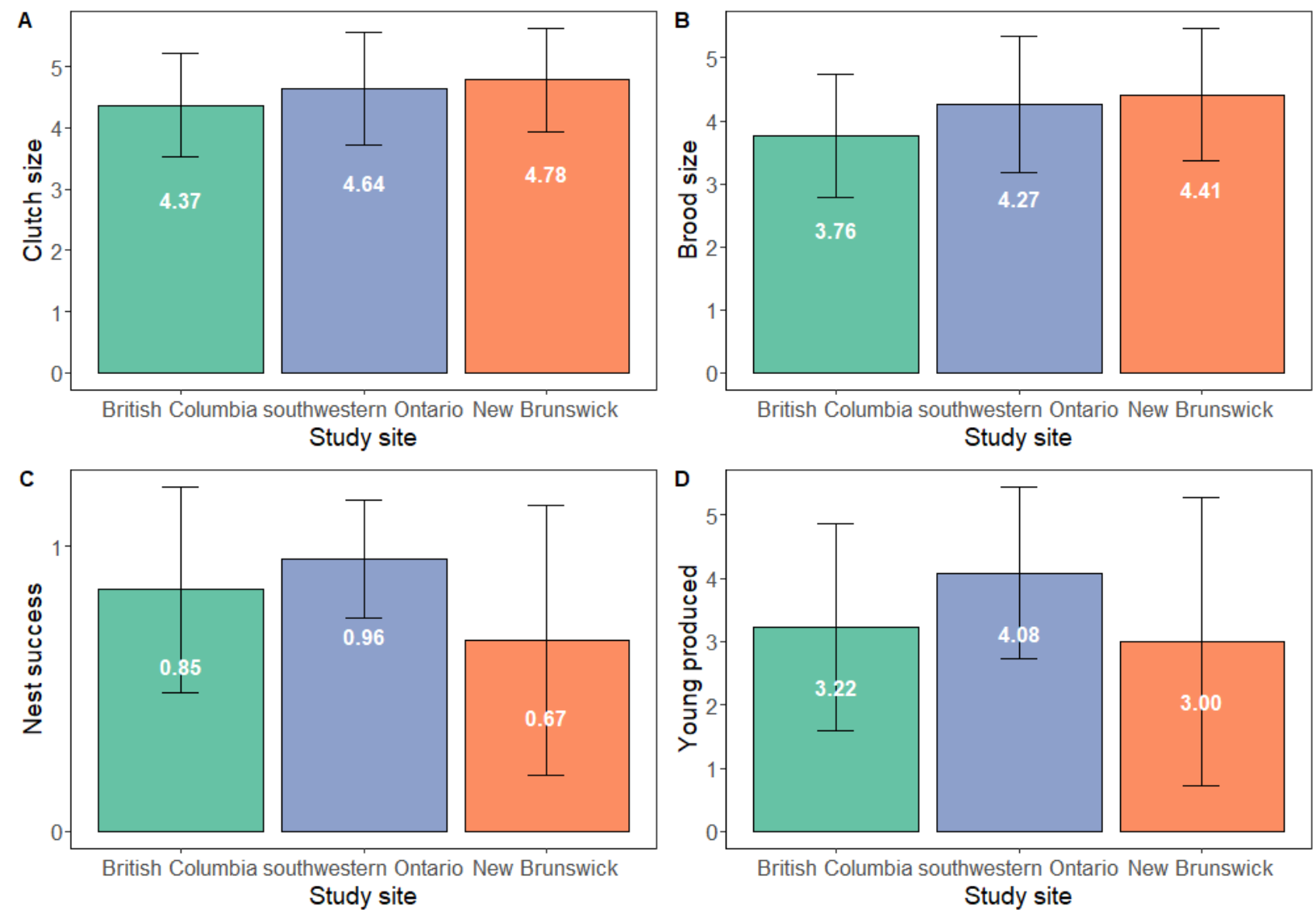

Figure A1.7. Mean + SD (error bars) of Barn Swallow breeding performance measures (A - clutch size, B - brood size, C - nest success and D - number of young produced) at study sites from 2013 to 2016. Mean values are indicated inside the bars in white. 

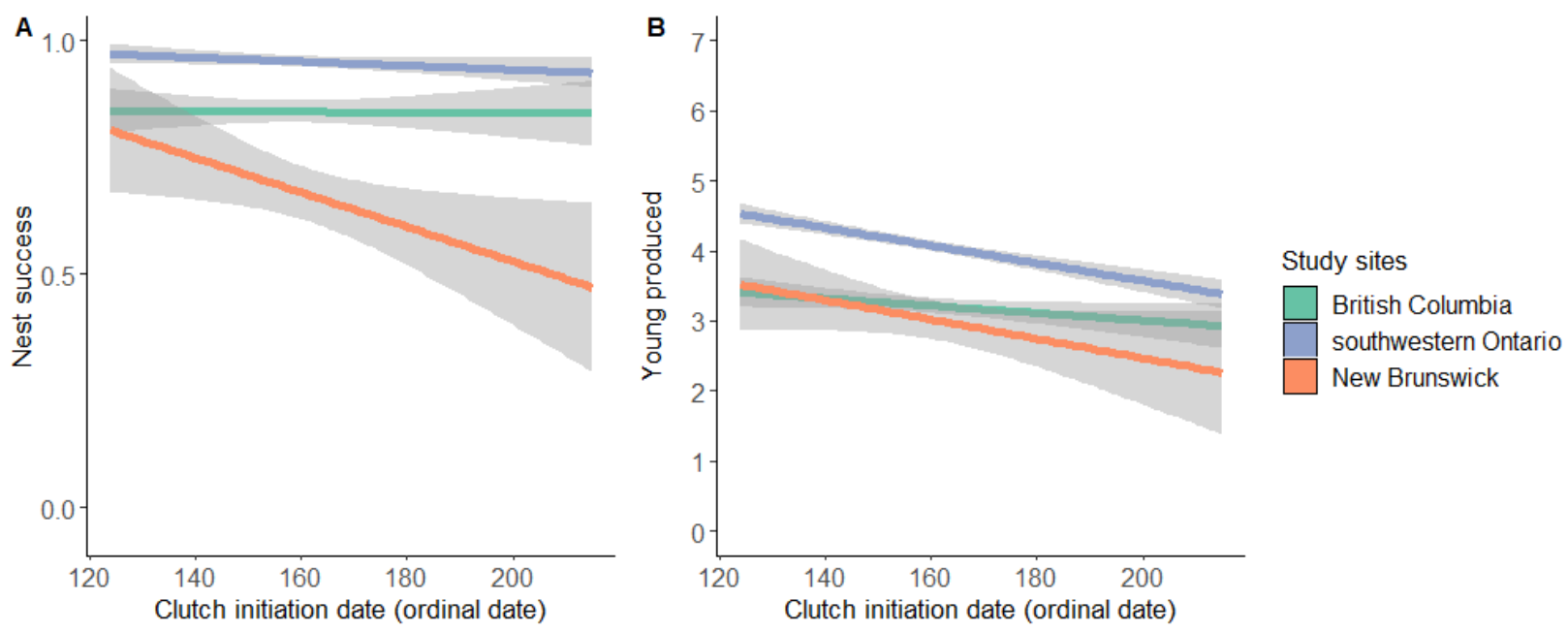

Figure A1.8. Relationship between Barn Swallow breeding performance ( $A$ - nest success, $B$ - number of young produced) and clutch initiation date at study sites from 2013 to 2016 . Shaded gray area around lines represent standard error. 
Table A1.1. Level of support for relationships between Barn Swallow breeding performance and spatial (study region) and temporal (clutch initiation date and year) factors, based on model selection.

Generalized linear mixed-models were used to estimate the relationships, with a binomial distribution for nest success and a zero-inflated Poisson distribution for number of young produced. Study region (British Columbia, southwestern Ontario and New Brunswick) and year (2013, 2014, 2015 and 2016) were treated as categorical variables. Clutch initiation date was treated as a continuous variable and was centred and scaled (standardized). An interaction term was included between study region and year in some candidate models. In all models, there was a random effect for colony. Presented here are the number of model parameters (k), small-samples Akaike's Information Criteria $\left(\mathrm{AlC}_{\mathrm{C}}\right)$, change in $\mathrm{AlC}_{\mathrm{C}}$ $(\triangle \mathrm{AIC})$, Akaike weights $\left(w_{i}\right)$ and log likelihood for each candidate model.

\begin{tabular}{llcccc}
\hline $\begin{array}{l}\text { Response } \\
\text { variable }\end{array}$ & Model & $\mathrm{k}$ & AICc & $\Delta$ AlCc & $w_{i}$ \\
\hline Nest & Region + Year + Clutch initiation date & 7 & 1527.61 & 0.00 & 0.35 \\
success & Region * Year + Clutch initiation date & 13 & 1527.79 & 0.18 & 0.32 \\
& Region * Year & 12 & 1529.02 & 1.40 & 0.17 \\
& Region + Year & 6 & 1529.27 & 1.66 & 0.15 \\
& Region + Clutch initiation date & 4 & 1545.38 & 17.77 & 0.00 \\
& Region & 3 & 1547.07 & 19.46 & 0.00 \\
& Clutch initiation date + Year & 5 & 1565.26 & 37.65 & 0.00 \\
& Year & 4 & 1567.39 & 39.78 & 0.00 \\
& Clutch initiation date & 2 & 1582.61 & 55.00 & 0.00 \\
Young & Intercept & 1 & 1584.63 & 57.02 & 0.00 \\
produced & Region * Year + Clutch initiation date & 13 & 9117.30 & 0.00 & 0.96 \\
& Region + Year + Clutch initiation date & 7 & 9123.62 & 6.32 & 0.04 \\
& Region + Clutch initiation date & 4 & 9131.62 & 14.33 & 0.00 \\
& Region * Year & 12 & 9136.56 & 19.27 & 0.00 \\
& Region + Year & 6 & 9143.09 & 25.79 & 0.00 \\
& Region & 3 & 9148.61 & 31.31 & 0.00 \\
& Clutch initiation date + Year & 5 & 9152.45 & 35.16 & 0.00 \\
& Clutch initiation date & 2 & 9158.96 & 41.66 & 0.00 \\
& Year & 4 & 9171.91 & 54.62 & 0.00 \\
& Intercept & 1 & 9176.00 & 58.71 & 0.00
\end{tabular}


Table A1.2. Model estimates and associated measures from best-fitting generalized linear mixed-models estimating the effect of spatial (study region) and temporal (clutch initiation date and year) factors on Barn Swallow breeding performance. In all models, there was a random effect for colony. British Columbia was the reference study region and 2013 was the reference year.

\begin{tabular}{|c|c|c|c|c|c|c|c|}
\hline $\begin{array}{l}\text { Respons } \\
\text { e } \\
\text { variable }\end{array}$ & Predictor variables & Estimate & SE & $\begin{array}{l}\text { Lower } \\
95 \% \mathrm{Cl}\end{array}$ & $\begin{array}{l}\text { Upper } \\
95 \% \mathrm{Cl}\end{array}$ & z & $P$ \\
\hline \multirow{7}{*}{$\begin{array}{l}\text { Nest } \\
\text { success }\end{array}$} & Intercept & 2.42 & 0.24 & 1.95 & 2.89 & 10.15 & $<0.001$ \\
\hline & Year - 2014 & -0.52 & 0.23 & -0.96 & -0.07 & -2.28 & 0.022 \\
\hline & Year - 2015 & -0.82 & 0.22 & -1.25 & -0.38 & -3.68 & $<0.001$ \\
\hline & Year - 2016 & -0.98 & 0.22 & -1.42 & -0.54 & -4.39 & $<0.001$ \\
\hline & Region - southwestern Ontario & 1.34 & 0.24 & 0.87 & 1.80 & 5.64 & $<0.001$ \\
\hline & Region - New Brunswick & -1.10 & 0.28 & -1.65 & -0.56 & -3.96 & $<0.001$ \\
\hline & Clutch initiation date & -0.14 & 0.07 & -0.27 & 0.00 & -1.93 & 0.054 \\
\hline \multirow{13}{*}{$\begin{array}{l}\text { Young } \\
\text { produce } \\
\text { d }\end{array}$} & Intercept & 1.40 & 0.04 & 1.32 & 1.47 & 36.18 & $<0.001$ \\
\hline & Year - 2014 & -0.02 & 0.05 & -0.12 & 0.08 & -0.46 & 0.648 \\
\hline & Year - 2015 & -0.22 & 0.06 & -0.33 & -0.11 & -3.84 & $<0.001$ \\
\hline & Year - 2016 & -0.23 & 0.06 & -0.34 & -0.11 & -3.76 & $<0.001$ \\
\hline & Region - southwestern Ontario & 0.02 & 0.05 & -0.07 & 0.12 & 0.45 & 0.651 \\
\hline & Region - New Brunswick & 0.01 & 0.09 & -0.17 & 0.18 & 0.10 & 0.923 \\
\hline & Clutch initiation date & -0.05 & 0.01 & -0.08 & -0.03 & -4.59 & $<0.001$ \\
\hline & $\begin{array}{l}\text { Year - } 2014 \text { : Region - } \\
\text { southwestern Ontario }\end{array}$ & 0.08 & 0.06 & -0.05 & 0.21 & 1.23 & 0.218 \\
\hline & $\begin{array}{l}\text { Year - } 2015 \text { : Region - } \\
\text { southwestern Ontario }\end{array}$ & 0.23 & 0.07 & 0.09 & 0.37 & 3.26 & 0.001 \\
\hline & $\begin{array}{l}\text { Year - } 2016 \text { : Region - } \\
\text { southwestern Ontario }\end{array}$ & 0.25 & 0.07 & 0.11 & 0.40 & 3.48 & 0.001 \\
\hline & $\begin{array}{l}\text { Year - } 2014 \text { : Region - New } \\
\text { Brunswick }\end{array}$ & 0.16 & 0.12 & -0.08 & 0.40 & 1.28 & 0.202 \\
\hline & $\begin{array}{l}\text { Year - } 2015 \text { : Region - New } \\
\text { Brunswick }\end{array}$ & 0.23 & 0.13 & -0.02 & 0.49 & 1.82 & 0.068 \\
\hline & $\begin{array}{l}\text { Year - } 2016 \text { : Region - New } \\
\text { Brunswick }\end{array}$ & 0.20 & 0.13 & -0.05 & 0.46 & 1.55 & 0.121 \\
\hline
\end{tabular}


Table A1.3. Type-III ANOVA results from best-fitting generalized linear mixed-models estimating the effect of spatial (study region) and temporal (clutch initiation date and year) factors on Barn Swallow breeding performance.

\begin{tabular}{llccc}
\hline $\begin{array}{l}\text { Respons } \\
\text { e } \\
\text { variable }\end{array}$ & Predictor variables & Df & $\begin{array}{c}\text { Chi- } \\
\text { square }\end{array}$ & $P$ \\
\hline Nest & Intercept & 1 & 103.10 & $<0.001$ \\
success & Year & 3 & 21.90 & $<0.001$ \\
& Region & 2 & 81.07 & $<0.001$ \\
& Clutch initiation date & 1 & 3.71 & 0.054 \\
Young & Intercept & 1 & 1309.30 & $<0.001$ \\
produce & Year & 3 & 27.51 & $<0.001$ \\
d & Region & 2 & 0.21 & 0.901 \\
& Clutch initiation date & 1 & 21.09 & $<0.001$ \\
& Year : Region & 6 & 18.43 & 0.005
\end{tabular}


Table A1.4. Level of support for relationships between average breeding performance factors and Barn Swallow annual indices in the subsequent year, based on model selection. General linear mixed-models were used to estimate the relationships with a normal distribution for annual indices and a random effect for year. Annual indices were calculated using a hierarchical Bayesian model with the firstdifference approach on BBS data collected in the strata that encompass each field site. Our breeding performance data were found in the British Columbia-BCR 5, Ontario-BCR 13 and New Brunswick-BCR 14 BBS strata. For each stratum, the annual indices were divided by the average annual index across the evaluated time period resulting in a response variable that represented deviations from the average annual index. An interaction term was included between breeding performance variables and study region in some candidate models. The breeding performance factors and year were treated as continuous variables and were centred and scaled (standardized). Presented here are the number of model parameters $(k)$, small-samples Akaike's Information Criteria $\left(A I C_{c}\right)$, change in AICC $\left(\triangle A I C_{c}\right)$, Akaike weights $\left(w_{i}\right)$ and log likelihood for each candidate model.

\begin{tabular}{lcccc}
\hline Model & $\mathrm{k}$ & $\mathrm{AICc}$ & $\Delta \mathrm{AICC}$ & $w_{i}$ \\
\hline Intercept & 1 & -52.96 & 0.00 & 0.98 \\
Mean colony size & 2 & -43.12 & 9.83 & 0.01 \\
Mean young produced & 2 & -42.95 & 10.01 & 0.01 \\
Mean nest success & 2 & -42.90 & 10.06 & 0.01 \\
Region & 3 & -36.44 & 16.52 & 0.00 \\
Mean colony size + Region & 4 & -26.27 & 26.69 & 0.00 \\
Mean young produced + Region & 4 & -26.00 & 26.96 & 0.00 \\
Mean nest success + Region & 4 & -25.85 & 27.10 & 0.00 \\
Mean nest success * Region & 6 & -11.32 & 41.63 & 0.00 \\
Mean young produced * Region & 6 & -10.05 & 42.90 & 0.00 \\
Mean colony size * Region & 6 & -8.24 & 44.72 & 0.00
\end{tabular}


British Columbia - BCR5

Antario - BCR13

- New Brunswick - BCR14
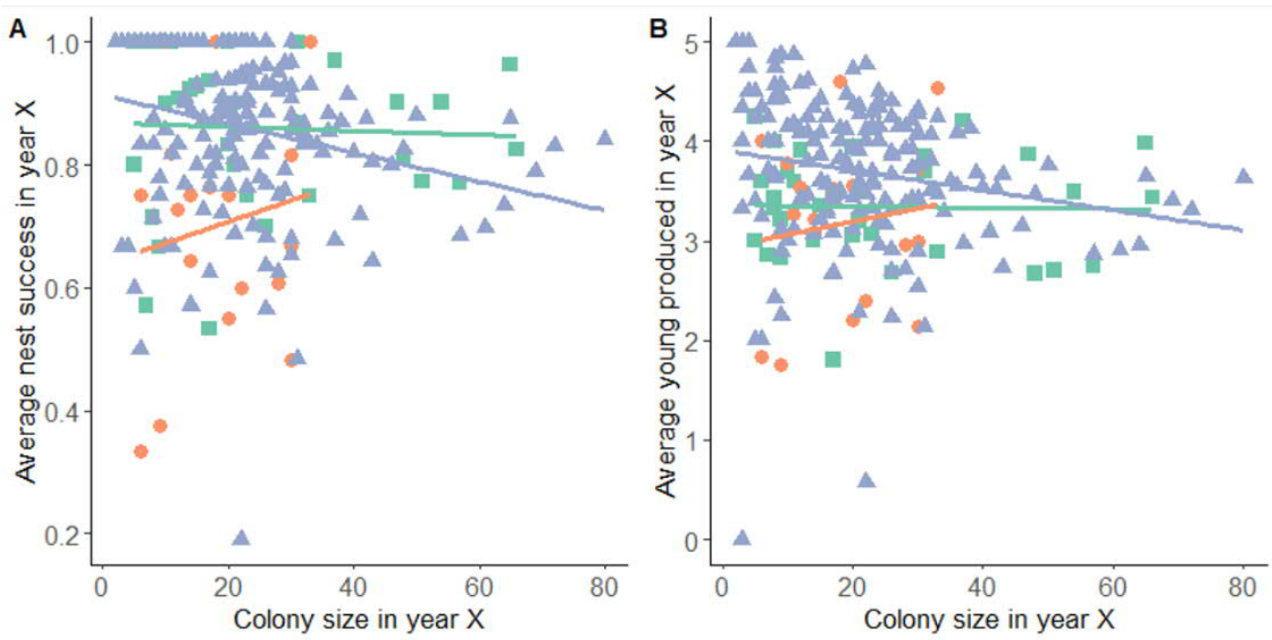

Figure A1.9. Relationship between colony size in year $X$ and breeding performance ( $A$ - nest success, B number of young produced) in year X from 2006 to 2018 to test for density dependence. 
Table A1.5. Level of support for relationships between local colony size from year $X$ and local breeding performance (nest success and young produced) in year $X$ to test density dependence. In models where nest success was the response variable, generalized linear mixed-models estimated the relationships and used a beta distribution. In models where young produced was the response variable, general linear mixed-models were used to estimate the relationships and used a normal distribution. An interaction term was included between colony size and study region in some candidate models. In all models, there was a random effect for colony. Presented here are the number of model parameters ( $\mathrm{k})$, small-samples Akaike's Information Criteria $\left(\mathrm{AIC}_{c}\right)$, change in $\mathrm{AICC}(\triangle \mathrm{AIC} C)$, Akaike weights $\left(w_{i}\right)$ and log likelihood for each candidate model.

\begin{tabular}{llcccc}
\hline Response variable & Model & $\mathrm{k}$ & $\mathrm{AICC}$ & $\Delta \mathrm{AICC}$ & $\boldsymbol{w}_{i}$ \\
\hline Nest success & Colony size * Region + Year & 17 & -402.92 & 0.00 & 0.35 \\
& Colony size * Region & 6 & -402.73 & 0.19 & 0.32 \\
& Colony size + Region & 4 & -401.88 & 1.04 & 0.21 \\
& Colony size + Region + Year & 15 & -400.55 & 2.37 & 0.11 \\
& Colony size & 2 & -393.94 & 8.98 & 0.00 \\
& Colony size + Year & 13 & -391.84 & 11.08 & 0.00 \\
& Region + Year & 14 & -387.41 & 15.51 & 0.00 \\
& Region & 3 & -382.74 & 20.18 & 0.00 \\
& Year & 12 & -379.96 & 22.96 & 0.00 \\
& Intercept & 1 & -376.60 & 26.32 & 0.00 \\
& Region & 3 & 510.85 & 0.00 & 0.51 \\
& Colony size + Region & 4 & 511.93 & 1.08 & 0.30 \\
& Intercept & 1 & 514.16 & 3.31 & 0.10 \\
& Colony size & 2 & 514.91 & 4.06 & 0.07 \\
& Colony size * Region & 6 & 516.63 & 5.78 & 0.03 \\
& Region + Year & 14 & 523.02 & 12.18 & 0.00 \\
& Year & 12 & 524.31 & 13.46 & 0.00 \\
& Colony size + Region + Year & 15 & 525.73 & 14.89 & 0.00 \\
& Colony size + Year & 13 & 526.10 & 15.25 & 0.00 \\
& Colony size * Region + Year & 17 & 531.03 & 20.18 & 0.00
\end{tabular}


Table A1.6. Model estimates and associated measures from the best-fitting models estimating the effect of local colony size, region and temporal factors (year) in year $\mathrm{X}$ on local breeding performance in year $\mathrm{X}$ at colonies to test density dependence. British Columbia was the reference study region and 2006 was the reference year in the models.

\begin{tabular}{llcccccc}
\hline $\begin{array}{l}\text { Response } \\
\text { variable }\end{array}$ & Predictor variables & Estimate & SE & $\begin{array}{c}\text { Lower } \\
95 \% \mathrm{Cl}\end{array}$ & $\begin{array}{c}\text { Upper } \\
95 \% \mathrm{Cl}\end{array}$ & z/t & $\mathrm{P}$ \\
\hline Nest & Intercept & 2.50 & 1.00 & 0.54 & 4.46 & 2.50 & 0.012 \\
Success & Colony size & -0.21 & 0.11 & -0.43 & 0.01 & -1.84 & 0.066 \\
& Region - New Brunswick & -0.61 & 0.27 & -1.14 & -0.09 & -2.30 & 0.022 \\
& Region - southwestern Ontario & 0.05 & 0.19 & -0.32 & 0.43 & 0.28 & 0.779 \\
& Year - 2007 & 0.00 & 1.20 & -2.35 & 2.35 & 0.00 & 1.000 \\
& Year - 2008 & -0.43 & 1.02 & -2.42 & 1.56 & -0.42 & 0.675 \\
& Year - 2009 & -0.96 & 1.01 & -2.94 & 1.03 & -0.95 & 0.345 \\
& Year - 2010 & -0.64 & 1.01 & -2.62 & 1.34 & -0.63 & 0.527 \\
& Year - 2011 & -0.90 & 1.00 & -2.86 & 1.07 & -0.89 & 0.371 \\
& Year - 2012 & -1.09 & 1.00 & -3.05 & 0.87 & -1.09 & 0.276 \\
& Year - 2013 & -0.28 & 1.00 & -2.23 & 1.67 & -0.28 & 0.779 \\
& Year - 2014 & -0.51 & 0.99 & -2.45 & 1.43 & -0.51 & 0.609 \\
& Year - 2015 & -0.97 & 0.99 & -2.92 & 0.97 & -0.98 & 0.327 \\
& Year - 2016 & -1.10 & 1.00 & -3.05 & 0.86 & -1.10 & 0.270 \\
& Year - 2017 & -1.08 & 1.02 & -3.09 & 0.92 & -1.06 & 0.290 \\
& Colony size : Region - New & 0.75 & 0.33 & 0.10 & 1.39 & 2.28 & 0.023 \\
& Brunswick & & & & & & \\
& Colony size : Region - southwestern & -0.09 & 0.13 & -0.34 & 0.17 & -0.68 & 0.495 \\
& Ontario & & & & & & \\
Young & Intercept & 3.35 & 0.14 & 3.07 & 3.62 & 24.23 & $<0.001$ \\
& Region - New Brunswick & -0.20 & 0.24 & -0.66 & 0.27 & -0.83 & 0.411 \\
& Region - southwestern Ontario & 0.37 & 0.15 & 0.07 & 0.67 & 2.39 & 0.021 \\
& & & & & & &
\end{tabular}


Table A1.7. Type-III ANOVA results from best-fitting models estimating the effect of local colony size, region and temporal factors (year) in year $\mathrm{X}$ on local breeding performance in year $\mathrm{X}$ at colonies to test density dependence.

\begin{tabular}{llccc}
\hline Response variable Predictor variables & Df & $\begin{array}{c}\text { Chi- } \\
\text { square }\end{array}$ & P \\
\hline Nest Success & Intercept & 1 & 6.25 & 0.012 \\
& Colony size & 1 & 3.37 & 0.066 \\
& Region & 2 & 9.88 & 0.007 \\
& Year & 11 & 25.51 & 0.008 \\
& Colony size : Region & 2 & 7.38 & 0.025 \\
Young produced & Intercept & 1 & 587.24 & $<0.001$ \\
& Region & 2 & 11.62 & 0.003
\end{tabular}


Table A1.8. Level of support for relationships between local breeding performance (mean nest success and mean young produced) in year $X$ and percentage point difference in local colony size from year $X$ to year $X+1$ to test recruitment. General linear mixed-models were used to estimate the relationships with a normal distribution for percentage point difference in colony size from year $X$ to year $X+1$ and a random effect for BBS strata (transect of province/territory and BCR) and colony; colony was nested in BBS stratum. Presented here are the number of model parameters ( $k$ ), small-samples Akaike's Information Criteria $(\mathrm{AIC})$, change in $\operatorname{AICC}(\triangle \mathrm{AIC})$, Akaike weights $\left(w_{i}\right)$ and log likelihood for each candidate model.

\begin{tabular}{lcccc}
\hline Model & $\mathrm{k}$ & $\mathrm{AICc}$ & $\Delta \mathrm{AICC}$ & $w_{i}$ \\
\hline Mean young produced + Year & 13 & 2147.51 & 0.00 & 0.70 \\
Mean nest success + Year & 13 & 2149.20 & 1.69 & 0.30 \\
Year & 12 & 2170.56 & 23.04 & 0.00 \\
Mean young produced & 2 & 2216.68 & 69.16 & 0.00 \\
Mean nest success & 2 & 2218.08 & 70.57 & 0.00 \\
Intercept & 1 & 2247.44 & 99.92 & 0.00
\end{tabular}


Table A1.9. Model estimates and associated measures from the best-fitting models estimating the effect of local breeding performance (mean nest success and mean young produced) in year $\mathrm{X}$ on the percentage point difference in local colony size from year $X$ to year $X+1$ to test recruitment. 2006 was the reference year in the models.

\begin{tabular}{lcccccc}
\hline Predictor variable & Estimate & SE & $\begin{array}{c}\text { Lower } \\
95 \% \mathrm{Cl}\end{array}$ & $\begin{array}{c}\text { Upper } \\
95 \% \mathrm{Cl}\end{array}$ & $\mathrm{t}$ & $\mathrm{P}$ \\
\hline Intercept & 8.94 & 33.25 & -56.23 & 74.12 & 0.27 & 0.788 \\
Mean young produced & 11.31 & 2.34 & 6.72 & 15.89 & 4.84 & $<0.001$ \\
Year - 2007 & 39.46 & 40.96 & -40.82 & 119.75 & 0.96 & 0.336 \\
Year - 2008 & 10.95 & 34.68 & -57.01 & 78.92 & 0.32 & 0.752 \\
Year-2009 & -13.93 & 34.61 & -81.77 & 53.91 & -0.40 & 0.688 \\
Year-2010 & -14.41 & 34.47 & -81.98 & 53.15 & -0.42 & 0.676 \\
Year-2011 & -1.09 & 34.10 & -67.94 & 65.75 & -0.03 & 0.974 \\
Year-2012 & -31.93 & 34.11 & -98.77 & 34.92 & -0.94 & 0.350 \\
Year-2013 & -2.86 & 33.78 & -69.07 & 63.35 & -0.09 & 0.933 \\
Year-2014 & -7.42 & 33.65 & -73.36 & 58.52 & -0.22 & 0.826 \\
Year-2015 & -9.49 & 33.66 & -75.46 & 56.48 & -0.28 & 0.778 \\
Year-2016 & -6.75 & 33.99 & -73.36 & 59.86 & -0.20 & 0.843 \\
Year-2017 & -20.67 & 35.26 & -89.78 & 48.45 & -0.59 & 0.558
\end{tabular}




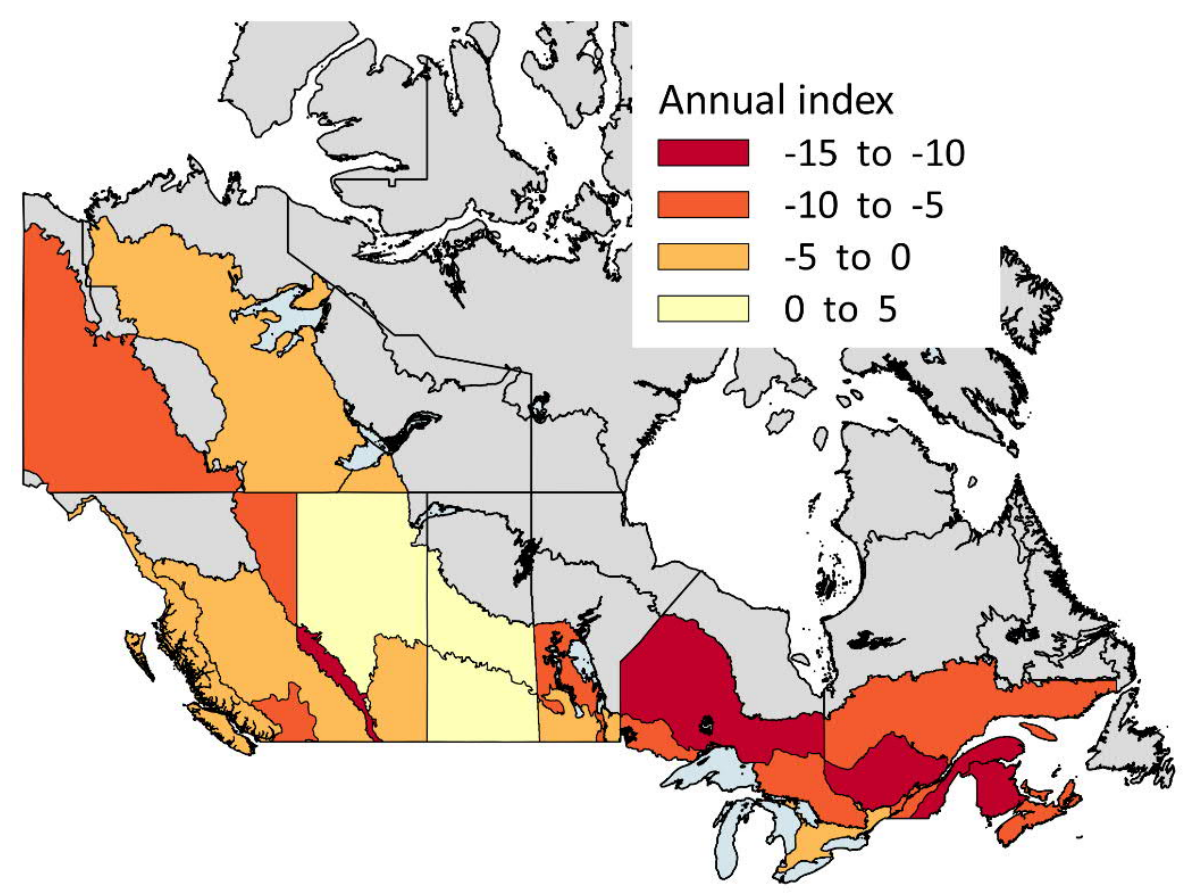

Figure A1.10. Average annual percent change in the Bank Swallow population in Canada from 1970 to 2018 stratified by intersections of region (state/province/territory) and BCR. The population trends use annual index data that represents the estimated average abundance of Bank Swallow on BBS routes run in a given year by an average observer in that stratum. The annual indices were calculated using hierarchical Bayesian models using the GAM approach. In regions shaded gray there are no BBS routes, Bank Swallows are not present or Bank Swallows have insufficient data. 


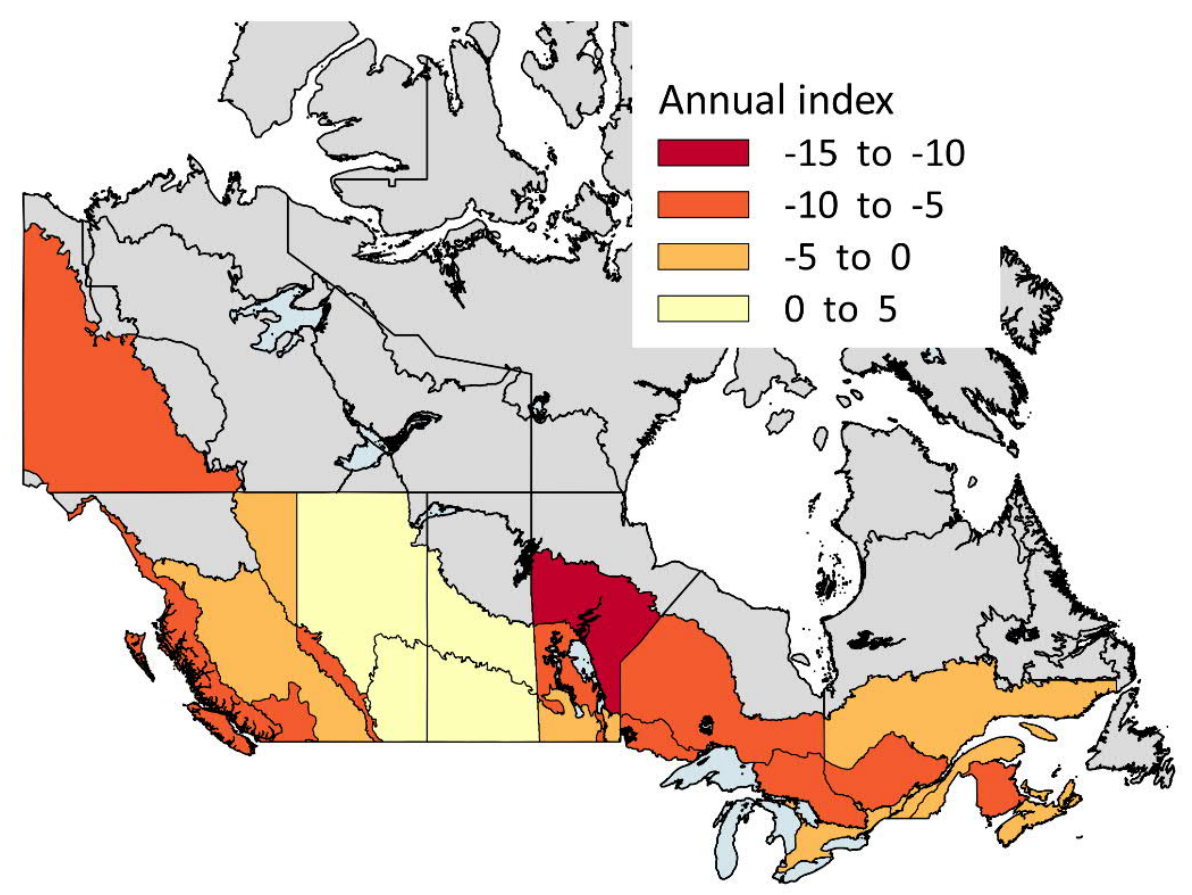

Figure A1.11. Average annual percent change in the Cliff Swallow population in Canada from 1970 to 2018 stratified by intersections of region (state/province/territory) and BCR. The population trends use annual index data that represents the estimated average abundance of Cliff Swallow on BBS routes run in a given year by an average observer in that stratum. The annual indices were calculated using hierarchical Bayesian models using the GAM approach. In regions shaded gray there are no BBS routes, Cliff Swallows are not present or Cliff Swallows have insufficient data. 


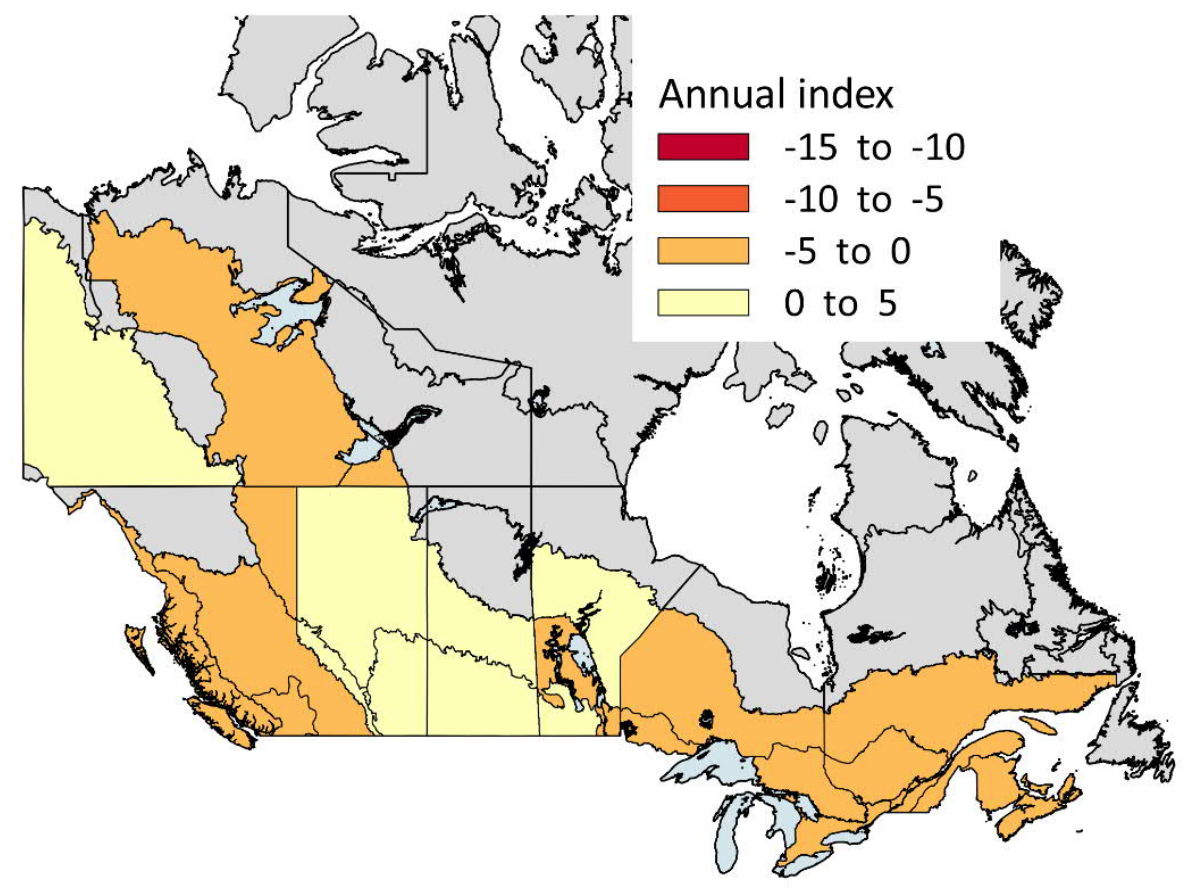

Figure A1.12. Average annual percent change in the Tree Swallow population in Canada from 1970 to 2018 stratified by intersections of region (state/province/territory) and BCR. The population trends use annual index data that represents the estimated average abundance of Tree Swallow on BBS routes run in a given year by an average observer in that stratum. The annual indices were calculated using hierarchical Bayesian models using the GAM approach. In regions shaded gray there are no BBS routes, Tree Swallows are not present or Tree Swallows have insufficient data. 


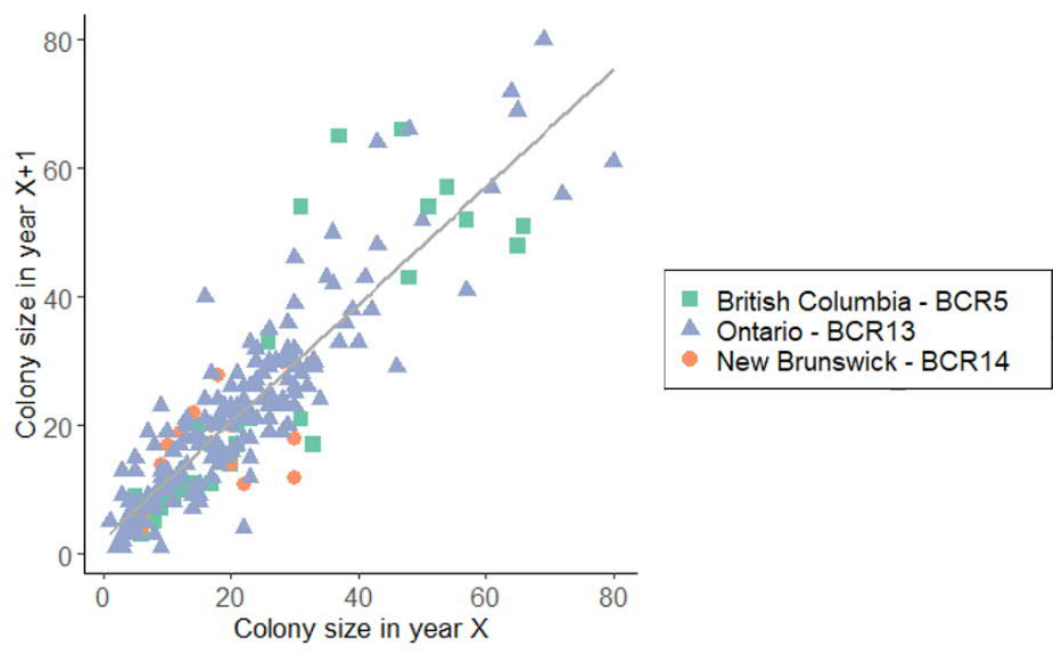

Figure A1.13. Relationship between colony size in year X and colony size in year X+1 from 2006 to 2018. The colony size per year was calculated. For each data point, the local colony size in year $X$ was linked to local colony size the following breeding season (i.e., year $\mathrm{X}+1$ ). 